\title{
Pesticide residues in agricultural crops (2014-2015)
}

\section{Pozostałości środków ochrony roślin w płodach rolnych (2014-2015)}

\author{
Anna Nowacka ${ }^{1 *}$, Agnieszka Hołodyńska-Kulas ${ }^{1}$, Dariusz Drożdżyński ${ }^{1}$, Monika Przewoźniak ${ }^{1}$, \\ Klaudia Pszczolińska², Bożena Łozowicka³ ${ }^{2}$ Piotr Kaczyński
}

\section{Summary}

In 2014 and 2015, the Institute of Plant Protection - National Research Institute as a part of the official control of plant protection products use conducted in primary production phase analysed 2699 samples of agricultural products collected from production sites all over the country. The study included 56 products and 368 active substances of plant protection products and their derivatives. Most of the tested samples were vegetables and fruits $(65.9 \%)$, while the remaining samples comprised of cereal grains $(28.2 \%)$, oilseeds (3.1\%), pulses (1.3\%), sugar plants (1.2\%) and spices (0.3\%). Residues of 77 compounds were detected in $27.5 \%$ of the samples. Overall, $98.6 \%$ of the analysed samples were compliant with the legal maximum residue limits (MRLS). The exceedances of the MRLs were found in $1.4 \%$ of the samples, while the residues of unauthorised plant protection product use in $8.5 \%$ of sample tested. Pesticide residues were detected in $44.3 \%$ of fruit samples, $24.8 \%$ of vegetable samples and $15.4 \%$ of cereal samples. They were also found in $21.4 \%$ of rapeseed samples, $18.8 \%$ of sugar plant samples, as well in $75.0 \%$ of spice samples. Pesticide residues were found most often in samples of gooseberries $(85.0 \%)$, currants $(64.6 \%)$, pears $(64.3 \%)$, grapes $(53.8 \%)$, celeriac $(51.0 \%)$, blueberries and strawberries $(50.0 \%)$. Dithiocarbamates $(8.8 \%)$, boscalid $(4.9 \%)$ and chlorpyrifos $(4.2 \%)$ were the most commonly detected substances.

Key words: crop protection products residues, fruits, vegetables, cereals, MRLs exceedances, unauthorised substances

\section{Streszczenie}

W latach 2014-2015 Instytut Ochrony Roślin - Państwowy Instytut Badawczy w ramach urzędowej kontroli pozostałości środków ochrony roślin prowadzonej na etapie produkcji pierwotnej przeanalizował 2699 próbek pobranych z gospodarstw produkcyjnych na terenie całego kraju. Badania objemowały 56 produktów i 368 substancji czynnych i/lub ich pochodnych. Większość badanych próbek stanowiły warzywa i owoce $(65,9 \%)$, pozostałe próbki - zboża $(28,2 \%)$, nasiona oleiste $(3,1 \%)$, nasiona roślin strączkowych $(1,3 \%)$, rośliny cukrodajne (1,2\%) i przyprawy (0,3\%). Łącznie wykryto 77 związków w 27,5\% badanych próbek. Ogółem, 98,6\% kontrolowanych próbek płodów rolnych spełniało wymagania dotyczące najwyższych dopuszczalnych pozostałości (NDP). Przekroczenia NDP stwierdzono w $1,4 \%$ próbek, natomiast pozostałości środków niedozwolonych w 8,5\% próbek. Pozostałości środków ochrony roślin wykryto w 44,3\% próbek owoców, 24,8\% próbek warzyw i 15,4\% próbek zbóż. Znaleziono je również w 21,4\% próbek rzepaku, 18,8\% próbek roślin cukrodajnych, a także w 75,0\% próbek przypraw. Pozostałości pestycydów najczęściej znajdowano w próbkach agrestu (85,0\%), porzeczek (64,6\%), gruszek $(64,3 \%)$, winogron $(53,8 \%)$, selera korzeniowego $(51,0 \%)$ oraz borówek i truskawek $(50,0 \%)$. Najczęściej wykrywano ditiokarbaminiany $(8,8 \%)$, boskalid $(4,9 \%)$ i chloropiryfos $(4,2 \%)$.

Słowa kluczowe: pozostałości środków ochrony roślin, owoce, warzywa, zboża, przekroczenia NDP, substancje niedozwolone

\author{
Instytut Ochrony Roślin - Państwowy Instytut Badawczy \\ Władysława Węgorka 20, 60-318 Poznań \\ ${ }^{2}$ Instytut Ochrony Roślin - Państwowy Instytut Badawczy, Oddział Sośnicowice \\ Gliwicka 29, 44-153 Sośnicowice \\ ${ }^{3}$ Instytut Ochrony Roślin - Państwowy Instytut Badawczy, Terenowa Stacja Doświadczalna w Białymstoku \\ Chełmońskiego 22, 15-195 Białystok \\ *corresponding author: a.nowacka@iorpib.poznan.pl \\ ORCID: 0000-0002-0255-5494
}




\section{Wstęp / Introduction}

Ochrona zdrowia ludzi i środowiska przed ewentualnymi niepożądanymi skutkami stosowania środków ochrony roślin (ś.o.r.) w rolnictwie jest ważnym zadaniem wszystkich państw członkowskich Unii Europejskiej. Zapewnienie bezpieczeństwa zdrowotnego konsumentów opiera się na szeroko zakrojonych badaniach pozostałości ś.o.r. w żywności i paszach na etapie ich produkcji i sprzedaży przeprowadzanych w ramach urzędowych kontroli. Badania mają ścisłe umocowania prawne i są nadzorowane przez Komisję Europejską. Obowiązek prowadzenia badań wynika zarówno z prawa krajowego, w szczególności ustawy z dnia 18 grudnia 2003 r. o ochronie roślin (Ustawa 2004) i ustawy z dnia 8 marca 2013 r. o środkach ochrony roślin (Ustawa 2013), jak i przepisów Unii Europejskiej, rozporządzenia Parlamentu Europejskiego i Rady (WE) nr 1107/2009 z dnia 21 października 2009 r. dotyczącego wprowadzania do obrotu środków ochrony roślin i uchylającego dyrektywy Rady 79/117/EWG i 91/414/EWG (Rozporządzenie 2009), dyrektywy Parlamentu Europejskiego i Rady 2009/128/WE z dnia 21 października 2009 r. ustanawiającej ramy wspólnotowego działania na rzecz zrównoważonego stosowania pestycydów (Dyrektywa 2009), rozporządzenia (WE) nr 396/2005 Parlamentu Europejskiego i Rady z dnia 23 lutego $2005 \mathrm{r}$. w sprawie najwyższych dopuszczalnych poziomów pozostałości pestycydów w żywności i paszy pochodzenia roślinnego i zwierzęcego oraz na ich powierzchni, zmieniającego dyrektywę Rady 91/414/EWG (Rozporządzenie 2005).

Przedstawione w pracy badania, przeprowadzone w ramach programu wieloletniego Instytutu Ochrony Roślin Państwowego Instytutu Badawczego (IOR - PIB) (Uchwała 2011), obejmowały lata 2014-2015 i zostały wykonane na rzecz urzędowej kontroli prowadzonej przez Państwową Inspekcję Ochrony Roślin i Nasiennictwa (PIORiN). Celem badań była ocena prawidłowości stosowania ś.o.r., czyli sprawdzenie przestrzegania przez producentów płodów rolnych zapisów art. 55 rozporządzenia odnośnie wprowadzania do obrotu środków ochrony roślin (Rozporządzenie 2009), art. 46 ustawy o środkach ochrony roślin (Ustawa 2013) oraz rozporządzenia w sprawie najwyższych dopuszczalnych poziomów pozostałości pestycydów w żywności i paszy pochodzenia roślinnego i zwierzęcego oraz na ich powierzchni (Rozporządzenie 2005). Badania miały na celu diagnozowanie zagrożeń związanych ze stosowaniem ś.o.r. i w efekcie podejmowanie sankcji wobec naruszających postanowienia wyżej wymienionego prawa, mających na celu zmobilizowanie rolników do przestrzegania zasad dobrej praktyki rolniczej. Chodziło przede wszystkim o wykrycie przypadków przekroczeń najwyższych dopuszczalnych poziomów pozostałości pestycydów (NDP), sygnalizowanych w formie powiadomień RASFF (Rapid Alert System for
Food and Feed) zgodnie z procedurą systemu wczesnego ostrzegania o niebezpiecznej żywności i paszach (Rozporządzenie 2002) i rozporządzeniem Komisji Unii Europejskiej (UE) ustanawiającym środki wykonawcze dla systemu wczesnego ostrzegania o niebezpiecznych produktach żywnościowych i środkach żywienia zwierząt (Rozporządzenie 2011), jak i krajowym - ustawą o bezpieczeństwie żywności i żywienia (Ustawa 2010).

\section{Materiały i metody / Materials and methods}

W latach 2014-2015, w trakcie urzędowej kontroli zbadano 2699 próbek płodów rolnych, pobranych na etapie produkcji pierwotnej, na zawartość pozostałości ś.o.r. Harmonogram pobierania próbek został opracowany przez Główny Inspektorat Ochrony Roślin i Nasiennictwa (GIORiN). Za ich pobór były odpowiedzialne Wojewódzkie Inspektoraty Ochrony Roślin i Nasiennictwa (WIORiN). Próbki pobierano zgodnie planem oraz zasadami określonymi w rozporządzeniu Ministerstwa Rolnictwa i Rozwoju Wsi (Rozporządzenie 2013) i analizowano w czterech laboratoriach IOR PIB zlokalizowanych w Poznaniu, Białymstoku, Rzeszowie i Sośnicowicach. Wyniki badań były na bieżąco przesyłane w formie sprawozdań z badań właściwym inspektoratom wojewódzkim, a o wykrytych przekroczeniach najwyższych dopuszczalnych poziomów pozostałości inspektoraty były informowane również $\mathrm{w}$ formie powiadomień RASFF, obowiązujących w unijnym systemie wczesnego ostrzegania o niebezpiecznej żywności i paszach.

Program badań obejmował 56 rodzajów płodów rolnych oraz 368 substancji czynnych ś.o.r. i/lub ich pochodnych i 5 innych (3 sejfnery, 1 synergetyk i 1 aktywator wzrostu roślin). Do badań pobrano 1167 próbek 28 gatunków warzyw, 612 próbek 15 gatunków owoców, 760 próbek 9 gatunków zbóż, które stanowiły odpowiednio - 43,2\%, 22,7\% i $28,2 \%$ ogółu analizowanych próbek. Pozostały, niewielki odsetek próbek $(5,9 \%)$ stanowiły próbki nasion rzepaku $(3,1 \%)$, grochu $(1,3 \%)$ i kminku $(0,3 \%)$ oraz korzenia buraka cukrowego $(1,2 \%)$. Ziarno pszenicy, kapusta pekińska, maliny, pomidory, pietruszka korzeniowa i seler korzeniowy były badane najczęściej. Spośród badanych substancji 154 stanowily insektycydy, akarycydy, nematocydy i rodentycydy, 112 - herbicydy i regulatory wzrostu roślin oraz 97 - fungicydy. Dane dotyczace liczby i rodzaju badanych próbek przedstawiono w tabeli 1., a listę oznaczanych związków w tabeli 2.

Do badań wykorzystano metody ilościowe, głównie wielopozostałościowe, w szczególności metody oparte na technice QuEChERS (Norma 2008; Walorczyk 2008; Walorczyk i Drożdżyński 2011), polegającej na wyizolowaniu pozostałości za pomocą rozpuszczalnika organicznego i oczyszczaniu ekstraktu techniką dyspersyjnej ekstrakcji 
Tabela 1. Badane produkty

Table 1. Analysed products

\begin{tabular}{|c|c|c|c|}
\hline \multirow[b]{2}{*}{ Produkt $^{1}$ - Product } & \multirow{2}{*}{$\begin{array}{c}\text { Liczba próbek } \\
\text { Number } \\
\text { of samples }\end{array}$} & \multicolumn{2}{|c|}{$\%$ próbek - Percentage of samples } \\
\hline & & $\mathrm{A} 2$ & B3 \\
\hline 1 & 2 & 3 & 4 \\
\hline Owoce - Fruits & 612 & 22,7 & - \\
\hline \multicolumn{4}{|c|}{ Owoce ziarnkowe - Pome fruits } \\
\hline Gruszki - Pears & 14 & 0,5 & 70,0 \\
\hline Jabłka - Apples & 6 & 0,2 & 30,0 \\
\hline \multicolumn{4}{|c|}{ Owoce pestkowe - Stone fruits } \\
\hline Brzoskwinie - Peaches & 46 & 1,7 & 19,1 \\
\hline Czereśnie - Sweet cherries & 83 & 3,1 & 34,4 \\
\hline Morele - Apricots & 34 & 1,3 & 14,1 \\
\hline Śliwki - Plums & 33 & 1,2 & 13,7 \\
\hline Wiśnie - Sour cherries & 45 & 1,7 & 18,7 \\
\hline \multicolumn{4}{|c|}{ Owoce jagodowe - Berries } \\
\hline Agrest - Gooseberries & 20 & 0,7 & 6,3 \\
\hline Borówka - Blueberries & 12 & 0,4 & 3,8 \\
\hline Maliny - Raspberries & 111 & 4,1 & 35,2 \\
\hline Porzeczki - Currants & 82 & 3,0 & 26,0 \\
\hline Truskawki - Strawberries & 64 & 2,4 & 20,3 \\
\hline Winogrona - Grapes & 26 & 1,0 & 8,3 \\
\hline \multicolumn{4}{|c|}{ Orzechy z drzew orzechowych - Tree nuts } \\
\hline Orzechy laskowe - Hazelnuts & 19 & 0,7 & 52,8 \\
\hline Orzechy włoskie - Walnuts & 17 & 0,6 & 47,2 \\
\hline Warzywa - Vegetables & 1167 & 43,2 & - \\
\hline \multicolumn{4}{|c|}{ Warzywa korzeniowe i bulwiaste - Root and tuber vegetables } \\
\hline Buraki ćwikłowe - Beetroots & 7 & 0,3 & 2,2 \\
\hline Chrzan - Horseradishes & 20 & 0,7 & 6,3 \\
\hline Marchew - Carrots & 28 & 1,0 & 8,8 \\
\hline Pasternak - Parsnips & 5 & 0,2 & 1,6 \\
\hline Pietruszka (korzeń) - Parsley (root) & 100 & 3,7 & 31,5 \\
\hline Rzodkiewka - Radish & 57 & 2,1 & 18,0 \\
\hline Seler korzeniowy - Celeriac & 100 & 3,7 & 31,5 \\
\hline \multicolumn{4}{|c|}{ Warzywa cebulowe - Bulb vegetables } \\
\hline Cebula - Onion & 44 & 1,6 & 83,0 \\
\hline $\begin{array}{l}\text { Dymka/cebula siedmiolatka i cebula szczypiorowa } \\
\text { Spring onions/green onions and welsh onions }\end{array}$ & 9 & 0,3 & 17,0 \\
\hline \multicolumn{4}{|c|}{ Warzywa owocowe - Fruiting vegetables } \\
\hline Bakłażan - Eggplants & 6 & 0,2 & 3,7 \\
\hline Ogórki - Cucumbers & 41 & 1,5 & 25,5 \\
\hline Papryka-Sweet pepper & 9 & 0,3 & 5,6 \\
\hline Pomidory - Tomatoes & 105 & 3,9 & 65,2 \\
\hline \multicolumn{4}{|c|}{ Warzywa kapustne - Brassica vegetables } \\
\hline Brokuły - Broccolis & 82 & 3,0 & 24,8 \\
\hline
\end{tabular}


Tabela 1. Badane produkty - cd.

Table 1. Analysed products - continued

\begin{tabular}{l|c|cc}
\hline \multicolumn{1}{c|}{1} & 2 & 3 & 4 \\
\hline Kalafior - Cauliflower & 42 & 1,6 & 12,7 \\
\hline Kapusta głowiasta - Head cabbage & 45 & 1,7 & 13,6 \\
\hline Kapusta brukselska - Brussels sprouts & 24 & 0,9 & 7,3 \\
\hline Kapusta pekińska - Chinese cabbage & 132 & 4,9 & 40,0 \\
\hline Rukola - Rucola & 5 & 0,2 & 1,5 \\
\hline
\end{tabular}

Rukola - Rucola

Warzywa liściowe i świeże zioła - Leaf vegetables and fresh herbs

\begin{tabular}{l|c|c|c}
\hline Koper - Dill & 82 & 3,0 & 40,8 \\
\hline Sałata - Lettuce & 64 & 2,4 & 31,8 \\
\hline Szczypiorek - Chives & 10 & 0,4 & 5,0 \\
\hline Szpinak - Spinach & 45 & 1,7 & 22,4 \\
\hline
\end{tabular}

Szpinak - Spinach

Warzywa strączkowe - Legume vegetables

\begin{tabular}{|c|c|c|c|}
\hline Bób - Broad bean & 24 & 0,9 & 33,3 \\
\hline Fasola szparagowa - String bean & 29 & 1,1 & 40,3 \\
\hline Groszek zielony - Green pea & 19 & 0,7 & 26,4 \\
\hline \multicolumn{4}{|c|}{ Warzywa łodygowe - Stem vegetables } \\
\hline Por - Leek & 25 & 0,9 & 75,8 \\
\hline Szparagi - Asparagus & 8 & 0,3 & 24,2 \\
\hline Nasiona roślin strączkowych - Pulses & 36 & 1,3 & - \\
\hline Groch - Pea & 36 & 1,3 & 100,0 \\
\hline Nasiona oleiste - Oilseeds & 84 & 3,1 & - \\
\hline Rzepak - Rapeseed & 84 & 3,1 & 100,0 \\
\hline Zboża-Cereals & 760 & 28,2 & - \\
\hline Gryka-Buckwheat & 22 & 0,8 & 2,9 \\
\hline Jęczmień - Barley & 81 & 3,0 & 10,7 \\
\hline Kukurydza - Corn & 65 & 2,4 & 8,6 \\
\hline Mieszanka zbożowa - Cereal mix & 66 & 2,4 & 8,7 \\
\hline Owies - Oat & 31 & 1,1 & 4,1 \\
\hline Proso - Common millet & 20 & 0,7 & 2,6 \\
\hline Pszenica - Wheat & 311 & 11,5 & 40,9 \\
\hline Pszenżyto - Triticale & 90 & 3,3 & 11,8 \\
\hline Żyto - Rye & 74 & 2,7 & 9,7 \\
\hline Rośliny cukrodajne - Sugar plants & 32 & 1,2 & - \\
\hline Burak cukrowy - Sugar beet root & 32 & 1,2 & 100,0 \\
\hline Przyprawy - Spices & 8 & $\mathbf{0 , 3}$ & - \\
\hline Kminek - Black caraway & 8 & 0,3 & 100,0 \\
\hline
\end{tabular}

'klasyfikacja produktów według Rozporządzenia (WE) 396/2005 - classification of products according to Regulation (EC) 396/2005 2procent całkowitej liczby badanych próbek - percentage of the total number of samples tested

${ }^{3}$ procent badanych próbek w danej grupie produktów - percentage of samples tested in individual product group

do fazy stałej (dSPE - dispersive solid-phase extraction). Badania instrumentalne wykonywano $\mathrm{z}$ wykorzystaniem chromatografii gazowej i cieczowej sprzężonej $\mathrm{z}$ tandemową kwadrupolową spektrometrią mas (GC-MS/MS, LC-MS/MS), chromatografii gazowej z detektorami wychwytu elektronów i termojonowym (GC-ECD/NPD) oraz chromatografii cieczowej $\mathrm{z}$ detektorem fotodiodowym (HPLC-PDA). W analizie pozostałości ditiokarbaminianów, oznaczanych jako $\mathrm{CS}_{2}$, zastosowano metodę spektrofotometryczną (Chmiel 1979). Metodyki badawcze spełniały wymagania określone w unijnych wytycznych dotyczących walidacji metod i procedur jakości w analizie żywności i pasz (Guidance 2013) i zostały akredytowane na zgodność z normą PN-EN ISO/IEC 17025:2005 przez Polskie Centrum Akredytacji (Norma 2005). Laboratoria biorące udział $\mathrm{w}$ badaniach potwierdzały kompetencje analityczne biorąc 
Tabela 2. Poszukiwane związki

Table 2. Analysed compounds

\begin{tabular}{|c|c|c|}
\hline 1. & Acephate & IN \\
\hline 2. & Acetamiprid* & IN \\
\hline 3. & Acetochlor & HB \\
\hline 4. & Acibenzolar-S-methyl & $\mathrm{PA}$ \\
\hline 5. & Acrinathrin & $\mathrm{AC}$ \\
\hline 6. & Aldicarb & NE, IN, AC \\
\hline 7. & Aldicarb sulfone & NE, IN, AC \\
\hline 8. & Aldicarb sulfoxide & NE, IN, AC \\
\hline 9. & Aldrin & IN \\
\hline 10. & Alpha-cypermetrin* & IN \\
\hline 11. & Ametryn & HB \\
\hline 12. & Amidosulfuron & HB \\
\hline 13. & Atrazine & FU \\
\hline 14. & Azaconazole & FU \\
\hline 15. & Azinphos-ethyl & $\mathrm{IN}, \mathrm{AC}$ \\
\hline 16. & Azinphos-methyl & $\mathrm{IN}, \mathrm{AC}$ \\
\hline 17. & Azoxystrobin* & $\mathrm{FU}$ \\
\hline 18. & Benalaxyl* & FU \\
\hline 19. & Bendiocarb & IN \\
\hline 20. & Bensulfuron-methyl & HB \\
\hline 21. & Benthiavalicarb isopropyl & FU \\
\hline 22. & Benzoximate & $\mathrm{AC}$ \\
\hline 23. & Beta-cyfluthrin* & $\mathrm{IN}$ \\
\hline 24. & Bifenthrin* & IN \\
\hline 25. & Bitertanol & $\mathrm{FU}$ \\
\hline 26. & Boscalid* & FU \\
\hline 27. & Bromacil & HB \\
\hline 28. & Bromophos-ethyl & IN \\
\hline 29. & Bromophos-methyl & $\mathrm{IN}$ \\
\hline 30. & Bromopropylate & $\mathrm{AC}$ \\
\hline 31. & Bromuconazole & $\mathrm{FU}$ \\
\hline 32. & Bupirimate* & $\mathrm{FU}$ \\
\hline 33. & Buprofezin* & $\mathrm{AC}, \mathrm{IN}$ \\
\hline 34. & Butafenacil & HB \\
\hline 35. & Buturon & HB \\
\hline 36. & Cadusafos & $\mathrm{IN}, \mathrm{NE}$ \\
\hline 37. & Captan* & $\mathrm{FU}$ \\
\hline 38. & Carbaryl* & IN \\
\hline 39. & Carbendazim* & $\mathrm{FU}$ \\
\hline 40. & Carbetamide & $\mathrm{HB}$ \\
\hline 41. & Carbofuran & IN, NE, AC \\
\hline 42. & Carbofuran-3-hydroxy & $\mathrm{IN}, \mathrm{NE}$ \\
\hline 43. & Carbosulfan & IN, NE \\
\hline 44. & Carboxin & $\mathrm{FU}$ \\
\hline 45. & Carfentrazone-ethyl & $\mathrm{HB}$ \\
\hline 46. & Chlorantraniliprole & $\mathrm{IN}$ \\
\hline 47. & Chlorbromuron & $\mathrm{HB}$ \\
\hline 48. & Chlorfenvinphos & IN \\
\hline
\end{tabular}

\begin{tabular}{|c|c|c|}
\hline 49. & Chloridazon & $\mathrm{HB}$ \\
\hline 50. & Chlorothalonil* & FU \\
\hline 51. & Chlorotoluron & HB \\
\hline 52. & Chloroxuron & $\mathrm{HB}$ \\
\hline 53. & Chlorpropham & PG, HB \\
\hline 54. & Chlorpyrifos* & $\mathrm{IN}, \mathrm{AC}$ \\
\hline 55. & Chlorpyrifos-methyl* & $\mathrm{IN}, \mathrm{AC}$ \\
\hline 56. & Chlorsulfuron & HB \\
\hline 57. & Chromafenozide & IN \\
\hline 58. & Cinosulfuron & HB \\
\hline 59. & Clodinafop-propargyl & HB \\
\hline 60. & Clofentezine & $\mathrm{AC}$ \\
\hline 61. & Clomazone & HB \\
\hline 62. & Clothianidin* & IN \\
\hline 63. & Crimidine & RO \\
\hline 64. & Cyanazine & HB \\
\hline 65. & Cyazofamid & FU \\
\hline 66. & Cycluron & $\mathrm{HB}$ \\
\hline 67. & Cyflufenamid & $\mathrm{FU}$ \\
\hline 68. & Cyfluthrin & $\mathrm{IN}$ \\
\hline 69. & Cymoxanil & FU \\
\hline 70. & Cypermethrin* & $\mathrm{IN}, \mathrm{AC}$ \\
\hline 71. & Cyprazine & $\mathrm{HB}$ \\
\hline 72. & Cyproconazole* & FU \\
\hline 73. & Cyprodinil* & FU \\
\hline 74. & $\begin{array}{l}\text { DDT (p,p'-DDD, } \\
\text { p,p'-DDE, o,p'-DDT, } \\
\text { p,p'-DDT) }\end{array}$ & IN \\
\hline 75. & Deltamethrin* & IN \\
\hline 76. & Demeton-S & IN \\
\hline 77. & Demeton-S-methyl sulfone & IN \\
\hline 78. & Desmedipham & $\mathrm{HB}$ \\
\hline 79. & Diazinon* & $\mathrm{IN}, \mathrm{AC}$ \\
\hline 80. & Dichlofluanid & FU \\
\hline 81. & Dichlorvos & $\mathrm{IN}, \mathrm{AC}$ \\
\hline 82. & Diclobutrazol & FU \\
\hline 83. & Dicloran & FU \\
\hline 84. & Dicofol & $\mathrm{AC}$ \\
\hline 85. & Dicrotophos & $\mathrm{IN}, \mathrm{AC}$ \\
\hline 86. & Dieldrin & IN \\
\hline 87. & Diethofencarb & FU \\
\hline 88. & Difenoconazole* & FU \\
\hline 89. & Difenoxuron & $\mathrm{HB}$ \\
\hline 90. & Diflubenzuron* & IN \\
\hline 91. & Diflufenican & $\mathrm{HB}$ \\
\hline 92. & Dimefuron & HB \\
\hline 93. & Dimethachlor & HB \\
\hline 94. & Dimethenamid & $\mathrm{HB}$ \\
\hline 95. & Dimethoate* & $\mathrm{IN}, \mathrm{AC}$ \\
\hline
\end{tabular}

\begin{tabular}{|c|c|c|}
\hline 96. & Dimethomorph* & FU \\
\hline 97. & Dimoxystrobin* & $\mathrm{FU}$ \\
\hline 98. & Diniconazole & $\mathrm{FU}$ \\
\hline 99. & Diphenylamine & PG \\
\hline 100. & $\begin{array}{l}\text { Dithiocarbamates } \text { (man- }^{-} \\
\text {cozeb, maneb, methiram, } \\
\text { propineb, thiram, ziram)* }\end{array}$ & $\mathrm{FU}$ \\
\hline 101. & Diuron & HB \\
\hline 102. & Endosulfan alpha & $\mathrm{IN}, \mathrm{AC}$ \\
\hline 103. & Endosulfan beta & $\mathrm{IN}, \mathrm{AC}$ \\
\hline 104. & Endosulfan-sulfate & $\mathrm{IN}, \mathrm{AC}$ \\
\hline 105. & Endrin & IN \\
\hline 106. & EPN & $\mathrm{IN}, \mathrm{AC}$ \\
\hline 107. & Epoxiconazole* & $\mathrm{FU}$ \\
\hline 108. & Esfenvalerate* & IN \\
\hline 109. & Etaconazole & FU \\
\hline 110. & Ethiofencarb & IN \\
\hline 111. & Ethiofencarb sulfone & IN \\
\hline 112. & Ethiofencarb sulfoxide & IN \\
\hline 113. & Ethion & $\mathrm{IN}, \mathrm{AC}$ \\
\hline 114. & Ethiprole & IN \\
\hline 115. & Ethirimol & $\mathrm{FU}$ \\
\hline 116. & Ethofumesate & $\mathrm{HB}$ \\
\hline 117. & Ethoprophos & NE, IN \\
\hline 118. & Etofenprox & IN \\
\hline 119. & Etoxazole & IN \\
\hline 120. & Famoxadon* & FU \\
\hline 121. & Fenamidone* & $\mathrm{FU}$ \\
\hline 122. & Fenamiphos & $\mathrm{NE}$ \\
\hline 123. & Fenarimol & $\mathrm{FU}$ \\
\hline 124. & Fenazaquin* & $\mathrm{AC}$ \\
\hline 125. & Fenbuconazole & $\mathrm{FU}$ \\
\hline 126. & Fenbutatin oxide & $\mathrm{AC}$ \\
\hline 127. & Fenchlorazole-ethyl & SA \\
\hline 128. & Fenchlorophos & IN \\
\hline 129. & Fenfuram & $\mathrm{FU}$ \\
\hline 130. & Fenhexamid* & $\mathrm{FU}$ \\
\hline 131. & Fenitrothion & $\mathrm{IN}, \mathrm{AC}$ \\
\hline 132. & Fenobucarb & IN \\
\hline 133. & Fenoxaprop-P & $\mathrm{HB}$ \\
\hline 134. & Fenoxaprop-P-ethyl & HB \\
\hline 135. & Fenoxycarb & IN \\
\hline 136. & Fenpropathrin & $\mathrm{IN}, \mathrm{AC}$ \\
\hline 137. & Fenpropidin* & $\mathrm{FU}$ \\
\hline 138. & Fenpropimorph & $\mathrm{FU}$ \\
\hline 139. & Fenpyroximate* & $\mathrm{AC}$ \\
\hline 140. & Fenthion & IN \\
\hline 141. & Fenuron & HB \\
\hline 142. & Fenvalerate* & $\mathrm{IN}, \mathrm{AC}$ \\
\hline
\end{tabular}


Tabela 2. Poszukiwane związki - cd.

Table 2. Analysed compounds - continued

\begin{tabular}{|c|c|c|c|c|c|c|c|c|}
\hline & & & & \\
\hline 143. & Fipronil & IN & 190. & Iprovalicarb & FU & 238. & Monocrotophos & $\mathrm{AC}, \mathrm{IN}$ \\
\hline 144. & Flazasulfuron & $\mathrm{HB}$ & 191. & Isocarbophos & IN & 239. & Monolinuron & $\mathrm{HB}$ \\
\hline 145. & Flonicamid* & IN & 192. & Isofenphos & IN & 240. & Monuron & HB \\
\hline 146. & Fluazifop & $\mathrm{HB}$ & 193. & Isofenphos-methyl & IN & 241. & Myclobutanil* & FU \\
\hline 147. & Flubendiamide & IN & 194. & Isoprocarb & IN & 242. & Napropamide & $\mathrm{HB}$ \\
\hline 148. & Fludioxonil* & FU & 195. & Isoprothiolane & $\mathrm{FU}$ & 243. & Nicosulfuron & $\mathrm{HB}$ \\
\hline 149. & Flufenacet & $\mathrm{HB}$ & 196. & Isoproturon & $\mathrm{HB}$ & 244. & Nitenpyram & IN \\
\hline 150. & Flumioxazin & $\mathrm{HB}$ & 197. & Isoxaben & $\mathrm{HB}$ & 245. & Nitrofen & $\mathrm{HB}$ \\
\hline 151. & Fluometuron & $\mathrm{HB}$ & 198. & Isoxadifen-ethyl & SA & 246. & Norflurazon & $\mathrm{HB}$ \\
\hline 152. & Fluopicolide* & $\mathrm{FU}$ & 199. & Kresoxim-methyl & $\mathrm{FU}$ & 247. & Omethoate & $\mathrm{IN}, \mathrm{AC}$ \\
\hline 153. & Fluoxastrobin & $\mathrm{FU}$ & 200. & Lambda-cyhalothrin* & $\mathrm{IN}$ & 248. & Oxadixyl & $\mathrm{FU}$ \\
\hline 154. & Fluquinconazole & FU & 201. & Lenacil* & $\mathrm{HB}$ & 249. & Oxamyl & $\mathrm{IN}, \mathrm{NE}$ \\
\hline 155. & Fluridone & $\mathrm{HB}$ & 202. & Linuron* & $\mathrm{HB}$ & 250. & Oxycarboxin & $\mathrm{FU}$ \\
\hline 156. & Flurochloridone* & HB & 203. & Lufenuron & IN & 251. & Oxydemeton-methyl & $\mathrm{IN}, \mathrm{AC}$ \\
\hline 157. & Flurtamone & $\mathrm{HB}$ & 204. & Malathion & $\mathrm{IN}, \mathrm{AC}$ & 252. & Paclobutrazol & $\mathrm{PG}, \mathrm{FU}$ \\
\hline 158. & Flusilazole & FU & 205. & Mandipropamid* & $\mathrm{FU}$ & 253. & Paraoxon-ethyl & $\mathrm{IN}, \mathrm{AC}$ \\
\hline 159. & Fluthiacet-methyl & $\mathrm{HB}$ & 206. & Mecarbam & $\mathrm{IN}, \mathrm{AC}$ & 254. & Paraoxon-methyl & IN, RE \\
\hline 160. & Flutolanil & $\mathrm{FU}$ & 207. & Mefenacet & $\mathrm{HB}$ & 255. & Parathion & $\mathrm{IN}, \mathrm{AC}$ \\
\hline 161. & Flutriafol* & $\mathrm{FU}$ & 208. & Mefenpyr-diethyl & SA & 256. & Parathion-methyl & IN, RE \\
\hline 162. & Folpet* & $\mathrm{FU}$ & 209. & Mepanipyrim & FU & 257. & Penconazole* & $\mathrm{FU}$ \\
\hline 163. & Forchlorfenuron & $\mathrm{PG}$ & 210. & Mepronil & FU & 258. & Pencycuron* & $\mathrm{FU}$ \\
\hline 164. & Formothion & $\mathrm{IN}, \mathrm{AC}$ & 211. & Mesosulfuron-methyl & $\mathrm{HB}$ & 259. & Pendimethalin* & $\mathrm{HB}$ \\
\hline 165. & Fosthiazate & $\mathrm{NE}$ & 212. & Mesotrione & $\mathrm{HB}$ & 260. & Permethrin & $\mathrm{IN}$ \\
\hline 166. & Fuberidazole & $\mathrm{FU}$ & \multirow{2}{*}{213.} & \multirow{2}{*}{$\begin{array}{l}\text { Metalaxyl (sum of metal- } \\
\text { axyl and, metalaxyl-M)* }\end{array}$} & \multirow{2}{*}{$\mathrm{FU}$} & 261. & Pethoxamid & $\mathrm{HB}$ \\
\hline 167. & Furalaxyl & IN & & & & 262. & Phenmedipham & HB \\
\hline 168. & Furathiocarb & IN & 214. & Metamitron & HB & 263. & Phenthoate & $\mathrm{IN}$ \\
\hline 169. & Halofenozide & $\mathrm{IN}$ & 215. & Metazachlor & $\mathrm{HB}$ & 264. & Phosalone & $\mathrm{IN}, \mathrm{AC}$ \\
\hline 170. & Haloxyfop-ethoxyethyl & $\mathrm{HB}$ & 216. & Metconazole & $\mathrm{FU}$ & 265. & Phosmet & IN \\
\hline 171. & Haloxyfop-methyl & FU & 217. & Methabenzthiazuron & $\mathrm{HB}$ & 266. & Phoxim & IN \\
\hline 172. & $\mathrm{HCB}$ & $\mathrm{HB}$ & 218. & Methacrifos & IN & 267. & Picoxystrobin* & $\mathrm{FU}$ \\
\hline 173. & HCH-alpha & IN & 219. & Methamidophos & IN & 268. & Piperonyl butoxide & SY \\
\hline 174. & HCH-beta & IN & 220. & Methidathion & IN & 269. & Pirimicarb desmethyl & $\mathrm{IN}$ \\
\hline 175. & $\begin{array}{l}\mathrm{HCH} \text {-gamma } \\
\text { (lindane) }\end{array}$ & IN, RO & 221. & Methiocarb & $\mathrm{IN}, \mathrm{RE}$ & 270. & Pirimicarb* & IN \\
\hline 176. & Heptachlor & IN & 222. & Methiocarb sulfone & $\mathrm{IN}, \mathrm{RE}$ & 271. & Prochloraz* & $\mathrm{FU}$ \\
\hline \multirow[b]{2}{*}{177.} & \multirow{2}{*}{$\begin{array}{l}\text { Heptachlor } \\
\text { endo-epoxide }\end{array}$} & \multirow[b]{2}{*}{ IN } & 223. & Methiocarb sulfoxide & $\mathrm{IN}, \mathrm{RE}$ & 272. & Procyazine & $\mathrm{HB}$ \\
\hline & & & 224. & Methomyl & $\mathrm{IN}$ & 273. & Procymidone & $\mathrm{FU}$ \\
\hline \multirow[b]{2}{*}{178.} & \multirow{2}{*}{$\begin{array}{l}\begin{array}{l}\text { Heptachlor } \\
\text { exo-epoxide }\end{array} \\
\end{array}$} & \multirow[b]{2}{*}{ IN } & 225. & Methoprotryne & $\mathrm{HB}$ & 274. & Profenofos & $\mathrm{IN}$ \\
\hline & & & 226. & Methoxychlor & IN & 275. & Promecarb & $\mathrm{IN}$ \\
\hline 179. & Heptenophos & IN & 227. & Methoxyfenozide & IN & 276. & Prometon & $\mathrm{HB}$ \\
\hline 180. & Hexaconazole & $\mathrm{FU}$ & 228. & Metobromuron & $\mathrm{HB}$ & 277. & Prometryn & $\mathrm{HB}$ \\
\hline 181. & Hexazinone & $\mathrm{HB}$ & 229. & Metolachlor & $\mathrm{HB}$ & 278. & Propachlor & $\mathrm{HB}$ \\
\hline 182. & Hexythiazox & $\mathrm{AC}, \mathrm{IN}$ & 230. & Metolcarb & IN & 279. & Propamocarb* & $\mathrm{FU}$ \\
\hline 183. & Imazalil & $\mathrm{FU}$ & 231. & Metosulam & $\mathrm{HB}$ & 280. & Propaquizafop & $\mathrm{HB}$ \\
\hline 184. & Imibenconazole & $\mathrm{FU}$ & 232. & Metoxuron & $\mathrm{HB}$ & 281. & Propargite & $\mathrm{AC}$ \\
\hline 185. & Imidacloprid* & IN & 233. & Metrafenone & FU & 282. & Propazine & $\mathrm{HB}$ \\
\hline 186. & Indoxacarb* & IN & 234. & Metribuzin* & $\mathrm{HB}$ & 283. & Propham & HB, PG \\
\hline 187. & Iodosulfuron-methyl & $\mathrm{HB}$ & 235. & Metsulfuron-methyl & $\mathrm{HB}$ & 284. & Propiconazole* & $\mathrm{FU}$ \\
\hline 188. & Ipconazole & $\mathrm{FU}$ & 236. & Mevinphos & $\mathrm{IN}, \mathrm{AC}$ & 285. & Propoxur & $\mathrm{IN}$ \\
\hline 189. & Iprodione* & FU & 237. & Mexacarbate & $\mathrm{IN}, \mathrm{AC}$ & 286. & Propyzamide & HB \\
\hline
\end{tabular}


Tabela 2. Poszukiwane związki - cd.

Table 2. Analysed compounds - continued

\begin{tabular}{|c|c|c|}
\hline 287. & Proquinazid & FU \\
\hline 288. & Prosulfocarb* & $\mathrm{HB}$ \\
\hline 289. & Prosulfuron & HB \\
\hline 290. & Prothiofos & IN \\
\hline 291. & Pyracarbolid & $\mathrm{FU}$ \\
\hline 292. & Pyraclostrobin* & FU \\
\hline 293. & Pyrazophos & FU \\
\hline 294. & Pyridaben* & $\mathrm{AC}, \mathrm{IN}$ \\
\hline 295. & Pyrimethanil* & $\mathrm{FU}$ \\
\hline 296. & Pyrimiphos-ethyl & $\mathrm{IN}$ \\
\hline 297. & Pyrimiphos-methyl* & IN \\
\hline 298. & Pyriproxyfen* & IN \\
\hline 299. & Quinalphos & IN \\
\hline 300. & Quinoclamine & HB \\
\hline 301. & Quinoxyfen & $\mathrm{FU}$ \\
\hline 302. & Quintozene & FU \\
\hline 303. & Rimsulfuron & $\mathrm{HB}$ \\
\hline 304. & Rotenone & IN \\
\hline 305. & Secbumeton & $\mathrm{HB}$ \\
\hline 306. & S-metolachlor & HB \\
\hline 307. & Siduron & $\mathrm{HB}$ \\
\hline 308. & Simazine & HB \\
\hline 309. & Simetryn & HB \\
\hline 310. & $\begin{array}{l}\text { Spinosad (sum of spinosyn } \\
\text { A and spinosyn D)* }\end{array}$ & IN \\
\hline 311. & Spirodiclofen* & $\mathrm{AC}, \mathrm{IN}$ \\
\hline 312. & Spiromesifen & $\mathrm{AC}, \mathrm{IN}$ \\
\hline 313. & Spirotetramat & IN \\
\hline 314. & Spiroxamine* & $\mathrm{FU}$ \\
\hline 315. & Sulcotrione & HB \\
\hline 316. & Sulfentrazone & $\mathrm{HB}$ \\
\hline 317. & Sulfometuron-methyl & $\mathrm{HB}$ \\
\hline
\end{tabular}

\begin{tabular}{|c|c|c|}
\hline 318. & Sulfosulfuron & $\mathrm{HB}$ \\
\hline 319. & Tau-fluvalinate & IN \\
\hline 320. & Tebuconazole* & IN \\
\hline 321. & Tebufenozide & IN \\
\hline 322. & Tebufenpyrad & $\mathrm{AC}$ \\
\hline 323. & Tebuthiuron & HB \\
\hline 324. & Tecnazene & $\mathrm{FU}$ \\
\hline 325. & Teflubenzuron & IN \\
\hline 326. & Tefluthrin & IN \\
\hline 327. & Tepraloxydim & $\mathrm{HB}$ \\
\hline 328. & Terbumeton & HB \\
\hline 329. & Terbuthylazine & HB \\
\hline 330. & Terbutryn & HB \\
\hline 331. & Tetrachlorvinphos & IN \\
\hline 332. & Tetraconazole* & FU \\
\hline 333. & Tetradifon & $\mathrm{AC}, \mathrm{IN}$ \\
\hline 334. & Tetramethrin & IN \\
\hline 335. & Thiabendazole & $\mathrm{FU}$ \\
\hline 336. & Thiacloprid* & IN \\
\hline 337. & Thiamethoxam* & IN \\
\hline 338. & Thidiazuron & PG \\
\hline 339. & Thifensulfuron-methyl & HB \\
\hline 340. & Thiobencarb & HB \\
\hline 341. & Thiodicarb & IN \\
\hline 342. & Thiofanox-sulfone & IN \\
\hline 343. & Thiofanox-sulfoxide & IN \\
\hline 344. & Thiophanate-ethyl & $\mathrm{FU}$ \\
\hline 345. & Thiophanate-methyl* & $\mathrm{FU}$ \\
\hline 346. & Tolclofos-methyl & $\mathrm{FU}$ \\
\hline 347. & Tolylfluanid & $\mathrm{FU}$ \\
\hline 348. & Tralkoxydim E & HB \\
\hline 349. & Tralkoxydim Z & HB \\
\hline
\end{tabular}

\begin{tabular}{c|l|c}
\hline 350. & Triadimefon & $\mathrm{FU}$ \\
\hline 351. & Triadimenol* & $\mathrm{FU}$ \\
\hline 352. & Triasulfuron & $\mathrm{HB}$ \\
\hline 353. & Triazophos & $\mathrm{IN}, \mathrm{AC}$ \\
\hline 354. & Triazoxide & $\mathrm{FU}$ \\
\hline 355. & Tribenuron-methyl & $\mathrm{HB}$ \\
\hline 356. & Tricyclazole & $\mathrm{FU}$ \\
\hline 357. & Trifloxystrobin* & $\mathrm{FU}$ \\
\hline 358. & Triflumizole & $\mathrm{FU}$ \\
\hline 359. & Triflumuron & $\mathrm{IN}$ \\
\hline 360. & Trifluralin & $\mathrm{HB}$ \\
\hline 361. & Triflusulfuron-methyl & $\mathrm{HB}$ \\
\hline 362. & Triforine & $\mathrm{FU}$ \\
\hline 363. & Trinexapac & $\mathrm{PG}$ \\
\hline 364. & Triticonazole* & $\mathrm{FU}$ \\
\hline 365. & Uniconazole & $\mathrm{PG}$ \\
\hline 366. & Vamidothion & $\mathrm{IN}, \mathrm{AC}$ \\
\hline 367. & Vinclozolin & $\mathrm{FU}$ \\
\hline 368. & Zoxamide & $\mathrm{FU}$ \\
\hline
\end{tabular}

${ }^{1}$ oznaczane jako pozostałości CS2 - determined as CS2 residues

*Związki wykryte - compounds detected

AC - akarycyd - acaricide

$\mathrm{FU}$ - fungicyd - fungicide

IN - insektycyd - insecticide

$\mathrm{H}$ - herbicyd - herbicide

$\mathrm{NE}$ - nematocyd - nematocide

PG - regulator wzrostu roślin - plant grow regulator

$\mathrm{RE}$ - repelent - repellent

$\mathrm{RO}$ - rodentycyd - rodencitide

PA - aktywator roślin - plant activator

SA - sejfner - safener

SY - synergetyk - synergist

systematycznie udział $\mathrm{w}$ międzynarodowych badaniach biegłości, organizowanych przez Laboratoria Referencyjne Unii Europejskiej ${ }^{1}$ i FAPAS $^{2}$.

${ }^{1}$ EURL-Proficiency Test-FV-16, 2014. Pesticide Residues in Sweet Pepper Homogenate. Final report.

EURL-Proficiency Test-FV-17, 2015. Pesticide Residues in Broccoli Homogenate. Final Report.

EUPT-CF8, 2014. Proficiency Test on incurred and spiked pesticides in wheat. Final report.

EUPT-CF9, 2015. Proficiency Test on pesticide residues in maize flour. Final report.

${ }^{2}$ FAPAS Proficiency Test 19173. Pesticide Residues in Tomato Purée. 2014. FAPAS Proficiency Test 19180. Pesticide Residues in Lettuce. 2014. FAPAS Proficiency Test 19185. Pesticide Residues in Spinach. 2015. FAPAS Proficiency Test 19187. Pesticide Residues in Pear. 2015. FAPAS Proficiency Test 19189. Pesticide Residues in Aubergine (Eggplant) Purée. 2015.
Wyniki badań były oceniane pod kątem spełnienia wymagań prawa żywnościowego w zakresie pozostałości ś.o.r. (Rozporządzenie 2005) zgodnie z zasadami podejmowania decyzji określonymi w przewodniku SANTE (Guidance 2013), stanowiącym unijne wytyczne dla urzędowych badań pozostałości pestycydów w żywności i paszach. Wykryte stężenie pozostałości uznawano za przekraczające NDP, niezgodne $\mathrm{z}$ wymaganiami, jeśli poziom pozostałości przekraczał najwyższy dopuszczalny poziom wziąwszy pod uwagę 50\% niepewność rozszerzoną (MU), tzn. gdy spełniona była nierówność: poziom pozostałości - MU > NDP. 


\section{Wyniki i dyskusja / Results and discussion}

Pozostałości ś.o.r. nie wykryto w 1958 próbkach płodów rolnych $(72,5 \%)$, natomiast stwierdzono w 741 próbkach (27,5\%). Próbki z jedną pozostałością stanowiły $15,1 \%$ badanych próbek, natomiast próbki z wieloma pozostałościami $12,3 \%$ - w tym głównie z dwoma (5,5\%), trzema $(3,5 \%)$ i czterema $(1,8 \%)$. W grupach produktów procent próbek z pozostałościami mieścił się w granicach 15,4-75,0\%. Najwyższy procent pozostałości wykryto w owocach $(45,4 \%)$, a także w przyprawach $(75,0 \%)$, stanowiących jednakże mało reprezentatywną grupę złożoną zaledwie z 8 próbek. Wyraźnie mniejszy odsetek próbek z pozostałościami ś.o.r. stwierdzono w grupie warzyw $(27,1 \%)$, nasion oleistych $(21,4 \%)$ i zbóż $(15,4 \%)$ oraz roślin cukrodajnych (18,8\%), a w grupie jadalnych nasion strączkowych pozostałości nie znaleziono. Częstość wykrywania pozostałości i przekroczeń NDP przedstawia rysunek 1., natomiast rozkład procentowy próbek z wieloma pozostałościami rysunek 2 .

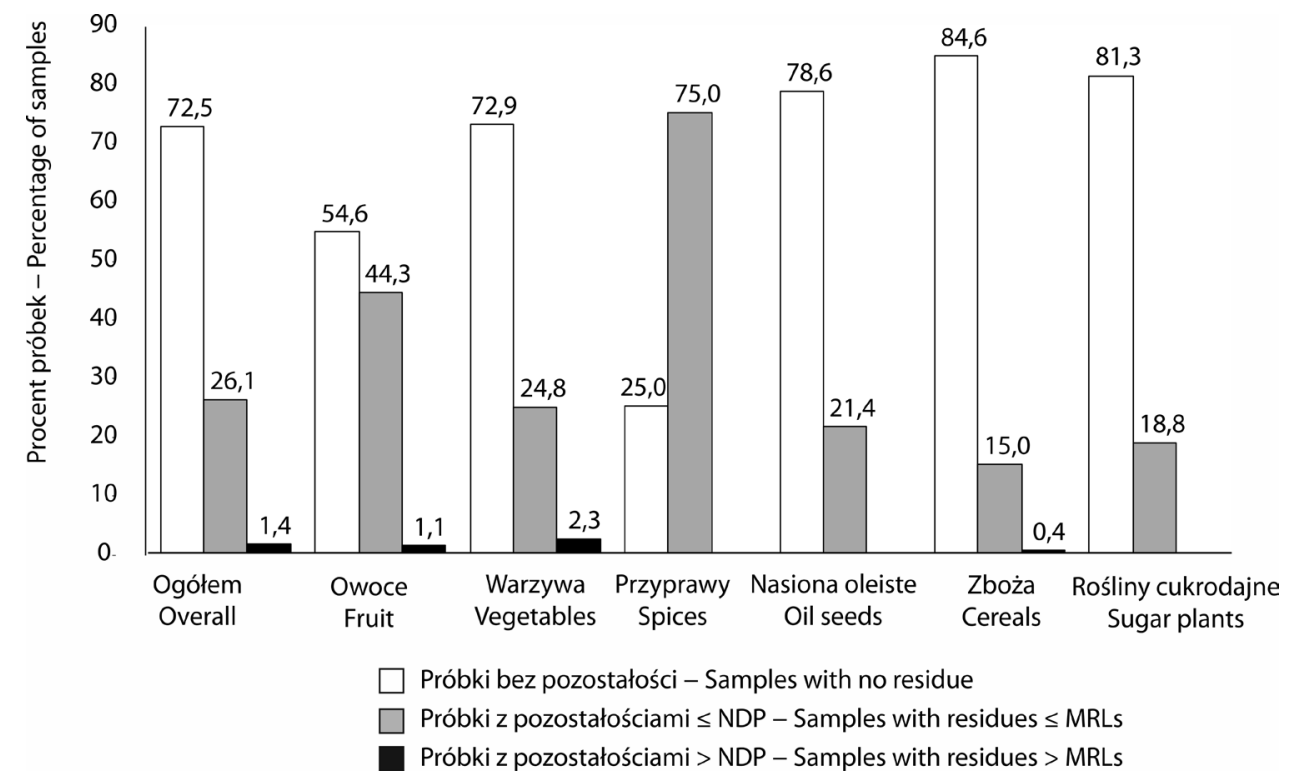

Rys. 1. Odsetek próbek z lub bez pozostałości oraz z pozostałościami przekraczającymi NDP w roku 2014 i 2015 (ogólny, grupy produktów)

Fig. 1. Percentage of samples with and without measurable residues, and residues exceeding the MRLs in 2014 and 2015 (total, product groups)
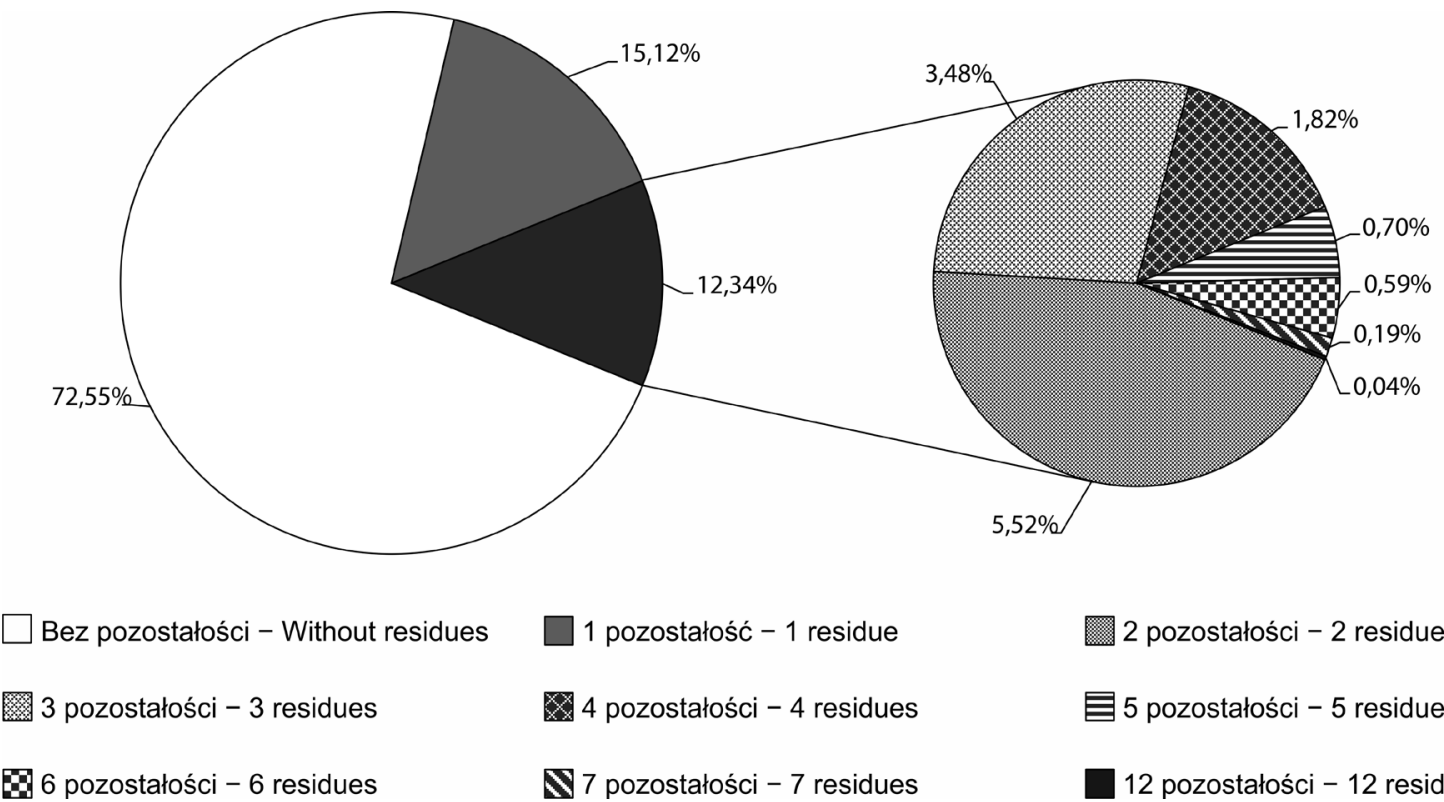

2 pozostałości -2 residues

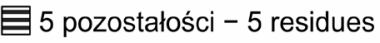

\$ 6 pozostałości -6 residues

$\mathbf{\$} 7$ pozostałości -7 residues

12 pozostałości -12 residues

Rys. 2. Odsetek próbek z wieloma pozostałościami (2014-2015)

Fig. 2. The percentage of samples with multiple residues (2014-2015) 
Pozostałości ś.o.r. stwierdzono w 49 spośród 56 badanych produktów (rys. 3). Częstość ich występowania była zróżnicowana $(2,2-85,0 \%)$, mieściła się w zakresie 2,2-20,0\% dla 23 produktów (kapusta głowiasta, mieszanka zbożowa, owies, fasola szparagowa, por, cebula, chrzan, kukurydza, gryka, proso, brokuły, szparagi, ogórki, żyto, groszek zielony, pszenżyto, bakłażan, morele, buraki cukrowe, pszenica, szczypiorek, rukola, pasternak) oraz w granicach $21,1-50,0 \%$ dla 20 produktów (rzodkiewki, rzepak nasiona, śliwki, jęczmień, sałata, szpinak, marchew, kapusta brukselska, dymka/cebula siedmiolatka i szczypiorowa, jabłka, kapusta pekińska, korzeń pietruszki, brzoskwinie, koper, wiśnie, pomidory, czereśnie, maliny, truskawki, borówki). Ponad połowa badanych próbek selera korzeniowego $(51,0 \%)$, winogron $(53,8 \%)$, gruszek $(64,3 \%)$, porzeczek $(64,6 \%)$, kminku $(75,0 \%)$ i agrestu $(85,0 \%)$ zawierała pozostałości ś.o.r.

Ogółem wykryto pozostałości 77 poszukiwanych związków - 40 fungicydów, 31 insektycydów i akarycydów oraz 6 herbicydów. Poszczególne substancje czynne wykrywano w 0,04-8,78\% próbek (rys. 4). Najczęściej stwierdzano pozostałości: ditiokarbaminianów $(8,8 \%)$, boskalidu $(4,9 \%)$, chloropiryfosu (4,2\%), azoksystrobiny (3,5\%), difenokonazolu $(2,8 \%)$, tebukonazolu $(2,7 \%)$, pirymifosu metylowego $(2,6 \%)$, cyprodynilu (2,5\%) i linuronu (2,1\%). Różnice w rodzaju i ilości występujących pozostałości w płodach rolnych wynikają z różnorodności substancji czynnych dopuszczonych do ochrony poszczególnych upraw, jak i terminów ich stosowania. Najszersze spektrum pozostałości stwierdzono w pomidorach (28 związków), w kapuście pekińskiej (24 związki) oraz w porzeczkach i selerze korzeniowym (21 związków). Czternaście substancji wykrywano w niektórych produktach z częstością równą lub wyższą 20\%: azoksystrobinę - w selerze korzeniowym, boskalid - w borówce, gruszkach, malinach i truskawkach, bupirymat - w agreście, cyprodynil - w borówkach i winogronach, chloropiryfos - w koprze, kminku i rukoli, difenokonazol w agreście i porzeczkach, ditiokarbaminiany - w agreście, gruszkach i porzeczkach, fludioksonil - w winogronach, kaptan - w gruszkach i wiśniach, linuron - w pasternaku i selerze korzeniowym, pirymetanil - w malinach, pirymifos metylowy - w kminku, piraklostrobinę - w gruszkach, trifloksystrobinę - w agreście i porzeczkach. Szczegółowe dane o odsetkach i zakresach wykrytych stężeń pozostałości w badanych produktach podano w tabeli 3 .

Badania wykazały występowanie nieprawidłowości dwojakiego rodzaju (przekroczenia NDP i obecność substancji niedopuszczonych do ochrony upraw). Wobec producentów nieprzestrzegających prawa, Państwowa Inspekcja Ochrony Roślin i Nasiennictwa podejmowała stosowne działania. Ogółem, wystawiono 37 powiadomień RASFF dla płodów rolnych zawierających pozostałości ś.o.r. przekraczające najwyższe dopuszczalne poziomy, wziąwszy pod uwagę 50\% niepewności pomiaru. Naruszenia NDP stanowiły niewielki odsetek próbek $(1,4 \%)$ i dotyczyły
16 rodzajów produktów z 3 badanych grup - warzyw (2,3\%), owoców $(1,1 \%)$ i zbóż $(0,4 \%)$ oraz 23 substancji czynnych (tab. 4, rys. 3, 4). W 32 próbkach stwierdzono poziom pozostałości wyższy od dopuszczalnego dla jednego związku, w 4 próbkach (kapusta pekińska, koper, porzeczki i proso) dla dwóch związków oraz w 1 próbce (maliny) dla trzech związków. Niedozwolone stężenia pozostałości ś.o.r. wykrywano głównie w koprze $(9,8 \%)$, szpinaku $(8,8 \%)$ i kapuście pekińskiej (5,4\%). Zdecydowana większość, tzn. 31 z 37 przekroczeń NDP $(83,8 \%)$, wynikała z zastosowania środków niedopuszczonych do ochrony uprawy, głównie preparatów zawierających chloropiryfos.

Więcej zaobserwowanych nieprawidłowości wiązało się z użyciem substancji niedozwolonych (tab. 5). W 230 próbkach $(8,5 \%)$ znaleziono pozostałości środków niedopuszczonych do ich ochrony, w 66 próbkach więcej niż jednego związku, maksymalnie aż siedmiu. Nieprawidłowości dotyczyły 66 substancji czynnych i 34 gatunków roślin uprawnych, warzywniczych (13,5\%), sadowniczych (10,0\%), zbożowych $(0,8 \%)$ i przyprawowych (62,5\%). Najwyraźniej problem zarysował się, odsetek naruszeń > 25\%, w przypadku upraw kminku (62,5\%), kopru (40,2\%), agrestu $(35,0 \%)$, marchwi $(28,6 \%)$, selera korzeniowego $(27,0 \%)$, kapusty pekińskiej $(26,5 \%)$ i brzoskwiń $(26,1 \%)$. W próbkach kapusty pekińskiej, selera korzeniowego i agrestu znaleziono kilkanaście niedopuszczonych substancji, odpowiednio - 17, 14 i 12. Prowadzone od lat przez IOR - PIB badania wskazują, że brak dostatecznego asortymentu środków do ochrony roślin małoobszarowych, przyczynia się do sięgania po środki niezalecane. Problem uwidocznił się wraz z wycofaniem z rynku unijnego wielu substancji czynnych ś.o.r. w wyniku oceny, mającej na celu pozostawienie w obrocie jedynie bezpiecznych dla ludzi i środowiska. Jedynym sposobem na ograniczanie tego niekorzystnego zjawiska jest stałe rozszerzanie dotychczasowych zezwoleń na zastosowania małoobszarowe. Proces ten postępuje, ale jest bardzo powolny. I choć pojawiają się nowe zastosowania w ochronie warzyw, owoców i ziół, to jednocześnie z obrotu znikają kolejne substancje czynne, co nie sprzyja odwróceniu niekorzystnego trendu w stosowaniu niedozwolonych praktyk w ochronie roślin. Z tym problemem borykają się również inne kraje członkowskie Unii Europejskiej, dlatego podjęto wspólnotowe działania na rzecz ograniczenia luk w obszarze małoobszarowych zastosowań ś.o.r. (Decyzja 2014; Report 2014).

Wyniki badań z lat 2014-2015 wykazały, że większość płodów rolnych $(98,6 \%)$ spełniała wymagania dotyczące najwyższych dopuszczalnych poziomów pozostałości, ponieważ były wolne od pozostałości lub ich stężenia mieściły się w normie. Wyniki świadczą o zmniejszeniu skali przekroczeń NDP i o wzroście przypadków stosowania środków niedozwolonych w porównaniu z 2013 rokiem, gdy te nieprawidłowości stanowiły odpowiednio 2,0 i 6,5\% (Nowacka i wsp. 2015). Kilkuprocentowy spadek przeciętnej 
Tabela 3. Pozostałości środków ochrony roślin wykryte w poszczególnych produktach Table 3. Pesticide residues detected in individual products

\begin{tabular}{|c|c|c|c|c|c|}
\hline \multirow{2}{*}{$\begin{array}{l}\text { Produkt } \\
\text { Product }\end{array}$} & \multirow{2}{*}{$\begin{array}{l}\text { Związek } \\
\text { Compound }\end{array}$} & \multirow{2}{*}{\begin{tabular}{|} 
Liczba badanych \\
próbek \\
Number of analysed \\
samples
\end{tabular}} & \multicolumn{2}{|c|}{$\begin{array}{l}\text { Próbki z pozostałościami } \\
\text { Samples with residues }\end{array}$} & \multirow{2}{*}{$\begin{array}{c}\text { Zakres wykrywanych } \\
\text { pozostałości } \\
\text { Range of found residues } \\
{[\mathrm{mg} / \mathrm{kg}]}\end{array}$} \\
\hline & & & $\begin{array}{c}\text { liczba } \\
\text { number }\end{array}$ & $\begin{array}{c}\text { procent } \\
\text { percentage }\end{array}$ & \\
\hline 1 & 2 & 3 & 4 & 5 & 6 \\
\hline \multicolumn{6}{|c|}{ Owoce - Fruits } \\
\hline \multicolumn{6}{|c|}{ Owoce ziarnkowe - Pome fruits } \\
\hline \multirow{10}{*}{ Gruszki - Pears } & boscalid & 14 & 3 & 21,4 & $0,02-0,21$ \\
\hline & captan & 14 & 3 & 21,4 & $0,02-0,11$ \\
\hline & carbendazim & 14 & 1 & 7,1 & 0,05 \\
\hline & cypermethrin & 14 & 1 & 7,1 & 0,03 \\
\hline & diflubenzuron & 14 & 1 & 7,1 & 0,19 \\
\hline & dithiocarbamates & 14 & 3 & 21,4 & $0,07-0,16$ \\
\hline & pirimicarb $^{1}$ & 14 & 2 & 14,3 & 0,03 \\
\hline & pyraclostrobin & 14 & 3 & 21,4 & $0,04-0,07$ \\
\hline & thiophanate-methyl & 14 & 1 & 7,1 & 0,06 \\
\hline & trifloxystrobin & 14 & 1 & 7,1 & 0,02 \\
\hline \multirow{2}{*}{ Jabłka - Apples } & captan & 6 & 1 & 16,7 & 0,04 \\
\hline & pirimicarb & 6 & 1 & 16,7 & 0,09 \\
\hline \multicolumn{6}{|c|}{ Owoce pestkowe - Stone fruits } \\
\hline \multirow{11}{*}{ Brzoskwinie - Peaches } & acetamiprid & 46 & 1 & 2,2 & 0,03 \\
\hline & boscalid & 46 & 1 & 2,2 & 0,18 \\
\hline & bupirimate $^{1}$ & 46 & 1 & 2,2 & 0,01 \\
\hline & $\operatorname{captan}^{1}$ & 46 & 6 & 13,0 & $0,04-0,35$ \\
\hline & carbendazim $^{1}$ & 46 & 9 & 19,6 & $0,01-0,09$ \\
\hline & cyprodinil & 46 & 1 & 2,2 & 0,02 \\
\hline & dithiocarbamates & 46 & 2 & 4,3 & $0,20-1,11$ \\
\hline & pirimicarb $^{1}$ & 46 & 5 & 10,9 & $0,01-0,03$ \\
\hline & pirydaben ${ }^{1}$ & 46 & 1 & 2,2 & 0,02 \\
\hline & tebuconazole $^{1}$ & 46 & 1 & 2,2 & 0,03 \\
\hline & thiophanate-methyl & 46 & 9 & 19,6 & $0,02-0,56$ \\
\hline \multirow{16}{*}{ Czereśnie - Sweet cherries } & acetamiprid & 83 & 14 & 16,9 & $0,007-0,11$ \\
\hline & alpha-cypermethrin $^{1}$ & 83 & 1 & 1,2 & 0,06 \\
\hline & beta-cyfluthrin ${ }^{1}$ & 83 & 1 & 1,2 & 0,07 \\
\hline & boscalid & 83 & 11 & 13,3 & $0,01-0,26$ \\
\hline & $\operatorname{captan}^{1}$ & 83 & 7 & 8,4 & $0,02-0,09$ \\
\hline & carbendazim $^{1}$ & 83 & 9 & 10,8 & $0,01-0,17$ \\
\hline & cypermethrin & 83 & 1 & 1,2 & 0,04 \\
\hline & cyprodinil & 83 & 3 & 3,6 & $0,07-0,14$ \\
\hline & deltamethrin & 83 & 1 & 1,2 & 0,02 \\
\hline & difenoconazole & 83 & 1 & 1,2 & 0,01 \\
\hline & dimethoate $^{1}$ & 83 & 1 & 1,2 & 0,03 \\
\hline & dithiocarbamates & 83 & 1 & 1,2 & 0,05 \\
\hline & fludioxonil & 83 & 2 & 2,4 & $0,04-0,05$ \\
\hline & iprodione & 83 & 1 & 1,2 & 0,77 \\
\hline & pirimicarb $^{1}$ & 83 & 5 & 6,0 & $0,01-0,03$ \\
\hline & pyraclostrobin & 83 & 7 & 8,4 & $0,007-0,07$ \\
\hline
\end{tabular}


Tabela 3. Pozostałości środków ochrony roślin wykryte w poszczególnych produktach - cd.

Table 3. Pesticide residues detected in individual products - continued

\begin{tabular}{|c|c|c|c|c|c|}
\hline 1 & 2 & 3 & 4 & 5 & 6 \\
\hline \multirow{3}{*}{ Czereśnie - Sweet cherries } & tebuconazole $^{1}$ & 83 & 5 & 6,0 & $0,01-0,12$ \\
\hline & thiacloprid & 83 & 8 & 9,6 & $0,01-0,15$ \\
\hline & thiophanate-methyl & 83 & 5 & 6,0 & $0,01-0,11$ \\
\hline \multirow{3}{*}{ Morele - Apricots } & $\operatorname{captan}^{1}$ & 34 & 4 & 11,8 & $0,02-0,59$ \\
\hline & cypermethrin & 34 & 1 & 2,9 & 0,03 \\
\hline & dithiocarbamates $^{1}$ & 34 & 2 & 5,9 & $0,35-0,43$ \\
\hline \multirow{7}{*}{ Śliwki - Plums } & acetamiprid & 33 & 1 & 3,0 & 0,01 \\
\hline & boscalid & 33 & 1 & 3,0 & 0,10 \\
\hline & carbendazim & 33 & 1 & 3,0 & 0,04 \\
\hline & dithiocarbamates & 33 & 3 & 9,1 & $0,05-0,18$ \\
\hline & spirodiclofen & 33 & 2 & 6,1 & $0,02-0,03$ \\
\hline & tebuconazole & 33 & 4 & 12,1 & $0,04-0,72$ \\
\hline & thiophanate-methyl & 33 & 1 & 3,0 & 0,04 \\
\hline \multirow{13}{*}{ Wiśnie - Sour cherries } & acetamiprid & 45 & 7 & 15,6 & $0,01-0,03$ \\
\hline & captan & 45 & 13 & 28,9 & $0,03-1,26$ \\
\hline & carbendazim & 45 & 5 & 11,1 & $0,02-0,07$ \\
\hline & cyprodinil & 45 & 1 & 2,2 & 0,08 \\
\hline & deltamethrin & 45 & 1 & 2,2 & 0,02 \\
\hline & difenoconazole & 45 & 4 & 8,9 & $0,01-0,27$ \\
\hline & dithiocarbamates & 45 & 4 & 8,9 & $0,13-0,32$ \\
\hline & pirimicarb $^{1}$ & 45 & 2 & 4,4 & 0,01 \\
\hline & pyrimethanil $^{1}$ & 45 & 1 & 2,2 & 0,01 \\
\hline & propiconazole & 45 & 1 & 2,2 & 0,10 \\
\hline & tebuconazole ${ }^{1}$ & 45 & 2 & 4,4 & $0,03-0,27$ \\
\hline & thiophanate-methyl & 45 & 1 & 2,2 & 0,02 \\
\hline & triadimenol & 45 & 6 & 13,3 & $0,01-0,09$ \\
\hline \multicolumn{6}{|c|}{ Owoce jagodowe - Berries } \\
\hline \multirow{19}{*}{ Agrest - Gooseberries } & alpha-cypermethrin & 20 & 1 & 5,0 & 0,05 \\
\hline & boscalid $^{1}$ & 20 & 2 & 10,0 & $0,06-0,19$ \\
\hline & bupirimate & 20 & 6 & 30,0 & $0,02-0,11$ \\
\hline & carbendazim & 20 & 1 & 5,0 & 0,07 \\
\hline & chlorpyrifos $^{1}$ & 20 & 2 & 10,0 & 0,01 \\
\hline & chlorpyrifos-methyl $^{1}$ & 20 & 1 & 5,0 & 0,01 \\
\hline & cyprodinil $^{1}$ & 20 & 2 & 10,0 & $0,02-0,10$ \\
\hline & cyproconazole $^{1}$ & 20 & 1 & 5,0 & 0,09 \\
\hline & difenoconazole & 20 & 8 & 40,0 & $0,01-0,07$ \\
\hline & dimoxystrobin & 20 & 1 & 5,0 & 0,07 \\
\hline & dithiocarbamates & 20 & 5 & 25,0 & $0,03-0,28$ \\
\hline & fludioxonil $^{1}$ & 20 & 1 & 5,0 & 0,07 \\
\hline & myclobutany $1^{1}$ & 20 & 1 & 5,0 & 0,18 \\
\hline & propiconazole $^{1}$ & 20 & 1 & 5,0 & 0,14 \\
\hline & pyraclostrobin $^{1}$ & 20 & 1 & 5,0 & 0,20 \\
\hline & tebuconazole ${ }^{1}$ & 20 & 1 & 5,0 & 0,05 \\
\hline & thiacloprid $^{1}$ & 20 & 1 & 5,0 & 0,07 \\
\hline & trifloxystrobin & 20 & 9 & 45,0 & $0,01-1,00$ \\
\hline & thiophanate-methyl ${ }^{1}$ & 20 & 1 & 5,0 & 0,12 \\
\hline
\end{tabular}


Tabela 3. Pozostałości środków ochrony roślin wykryte w poszczególnych produktach - cd.

Table 3. Pesticide residues detected in individual products - continued

\begin{tabular}{|c|c|c|c|c|c|}
\hline 1 & 2 & 3 & 4 & 5 & 6 \\
\hline \multirow{5}{*}{ Borówka - Blueberries } & boscalid & 12 & 6 & 50,0 & $0,01-0,19$ \\
\hline & cyprodinil & 12 & 3 & 25,0 & 0,02 \\
\hline & fludioxonil & 12 & 1 & 8,3 & 0,05 \\
\hline & iprodione & 12 & 1 & 8,3 & 0,17 \\
\hline & pyraclostrobin & 12 & 1 & 8,3 & 0,04 \\
\hline \multirow{14}{*}{ Maliny - Raspberries } & boscalid & 111 & 30 & 27,0 & $0,02-4,79$ \\
\hline & captan $^{1}$ & 111 & 2 & 1,8 & $0,02-0,05$ \\
\hline & chlorpyrifos $^{1}$ & 111 & 1 & 0,9 & 0,04 \\
\hline & cyprodinil & 111 & 17 & 15,3 & $0,02-0,85$ \\
\hline & fenazaquin ${ }^{1}$ & 111 & 1 & 0,9 & 0,06 \\
\hline & fenhexamid & 111 & 4 & 3,6 & $0,24-1,42$ \\
\hline & fludioxonil & 111 & 11 & 11,7 & $0,01-0,32$ \\
\hline & flutriafol $^{1}$ & 111 & 1 & 0,9 & 0,14 \\
\hline & folpet & 111 & 1 & 0,9 & 0,28 \\
\hline & iprodione & 111 & 6 & 5,4 & $0,04-1,42$ \\
\hline & penconazole $^{1}$ & 111 & 1 & 0,9 & 0,35 \\
\hline & pyraclostrobin & 111 & 6 & 5,4 & $0,01-0,20$ \\
\hline & pyrimethanil & 111 & 31 & 27,9 & $0,01-0,79$ \\
\hline & spirodiclofen $^{1}$ & 111 & 3 & 2,7 & $0,04-0,08$ \\
\hline \multirow{21}{*}{ Porzeczki - Currants } & acetamiprid & 82 & 4 & 4,9 & $0,01-0,02$ \\
\hline & bifenthrin ${ }^{1}$ & 82 & 1 & 1,2 & 0,03 \\
\hline & boscalid & 82 & 4 & 4,9 & $0,06-1,29$ \\
\hline & bupirimate & 82 & 1 & 1,2 & 0,03 \\
\hline & chlorpyrifos $^{1}$ & 82 & 1 & 1,2 & 0,06 \\
\hline & cypermethrin & 82 & 6 & 7,3 & $0,03-0,30$ \\
\hline & cyprodinil & 82 & 4 & 4,9 & $0,01-0,10$ \\
\hline & deltamethrin & 82 & 5 & 6,1 & $0,03-0,06$ \\
\hline & difenoconazole & 82 & 34 & 41,5 & $0,01-0,25$ \\
\hline & dithiocarbamates & 82 & 32 & 39,0 & $0,05-3,60$ \\
\hline & esfenvalerate & 82 & 1 & 1,2 & 0,01 \\
\hline & fenpyroximate & 82 & 8 & 9,8 & $0,02-0,43$ \\
\hline & fludioxonil & 82 & 1 & 1,2 & 0,26 \\
\hline & indoxacarb & 82 & 1 & 1,2 & 0,13 \\
\hline & lambda-cyhalothrin ${ }^{1}$ & 82 & 9 & 11,0 & $0,01-0,03$ \\
\hline & pyraclostrobin & 82 & 4 & 4,9 & $0,12-0,61$ \\
\hline & spirodiclofen & 82 & 4 & 4,9 & $0,18-0,25$ \\
\hline & tebuconazole ${ }^{1}$ & 82 & 1 & 1,2 & 0,02 \\
\hline & thiacloprid & 82 & 14 & 17,1 & $0,01-0,2$ \\
\hline & thiophanate-methyl ${ }^{1}$ & 82 & 1 & 1,2 & 0,65 \\
\hline & trifloxystrobin & 82 & 25 & 30,5 & $0,01-0,25$ \\
\hline \multirow{7}{*}{ Truskawki - Strawberries } & acetamiprid & 64 & 1 & 1,6 & 0,02 \\
\hline & azoxystrobin & 64 & 3 & 4,7 & $0,02-0,07$ \\
\hline & boscalid & 64 & 15 & 23,4 & $0,01-0,76$ \\
\hline & bupirimate & 64 & 1 & 1,6 & 0,02 \\
\hline & captan & 64 & 1 & 1,6 & 0,14 \\
\hline & chlorpyrifos $^{1}$ & 64 & 1 & 1,6 & 0,01 \\
\hline & cypermethrin & 64 & 1 & 1,6 & 0,02 \\
\hline
\end{tabular}


Tabela 3. Pozostałości środków ochrony roślin wykryte w poszczególnych produktach - cd.

Table 3. Pesticide residues detected in individual products - continued

\begin{tabular}{|c|c|c|c|c|c|}
\hline 1 & 2 & 3 & 4 & 5 & 6 \\
\hline \multirow{10}{*}{ Truskawki - Strawberries } & cyprodinil & 64 & 11 & 17,2 & $0,02-0,26$ \\
\hline & difenoconazole & 64 & 3 & 4,7 & $0,02-0,04$ \\
\hline & dithiocarbamates & 64 & 6 & 9,4 & $0,07-0,59$ \\
\hline & fenhexamid & 64 & 1 & 1,6 & 0,01 \\
\hline & fludioxonil & 64 & 11 & 17,2 & $0,02-0,18$ \\
\hline & folpet $^{1}$ & 64 & 3 & 4,7 & $0,02-0,15$ \\
\hline & iprodione & 64 & 1 & 1,6 & 0,06 \\
\hline & pyrimethanil & 64 & 6 & 9,4 & $0,01-0,33$ \\
\hline & tetraconazole & 64 & 2 & 3,1 & 0,01 \\
\hline & trifloxystrobin & 64 & 3 & 4,7 & $0,01-0,15$ \\
\hline \multirow{17}{*}{ Winogrona - Grapes } & azoxystrobin $^{1}$ & 26 & 2 & 7,7 & $0,02-0,33$ \\
\hline & boscalid ${ }^{1}$ & 26 & 1 & 3,8 & 0,64 \\
\hline & captan $^{1}$ & 26 & 1 & 3,8 & 0,61 \\
\hline & carbendazim & 26 & 1 & 3,8 & 0,02 \\
\hline & cyprodinil & 26 & 8 & 30,8 & $0,09-0,39$ \\
\hline & difenoconazole ${ }^{1}$ & 26 & 1 & 3,8 & 0,18 \\
\hline & dimethomorph $^{1}$ & 26 & 1 & 3,8 & 0,04 \\
\hline & dithiocarbamates & 26 & 5 & 19,2 & $0,03-0,24$ \\
\hline & fenhexamid $^{1}$ & 26 & 2 & 7,7 & $0,04-1,74$ \\
\hline & fludioxonil & 26 & 6 & 23,1 & $0,05-0,16$ \\
\hline & folpet $^{1}$ & 26 & 2 & 7,7 & $0,02-0,22$ \\
\hline & iprodione & 26 & 2 & 7,7 & $0,09-0,26$ \\
\hline & lenacil $^{1}$ & 26 & 1 & 3,8 & 0,07 \\
\hline & metalaxyl & 26 & 4 & 15,4 & $0,01-0,02$ \\
\hline & pyrimethanil & 26 & 2 & 7,7 & $0,30-0,49$ \\
\hline & tebuconazole ${ }^{1}$ & 26 & 1 & 3,8 & 0,68 \\
\hline & trifloxystrobin $^{1}$ & 26 & 1 & 3,8 & 0,32 \\
\hline
\end{tabular}

Warzywa - Vegetables

Warzywa korzeniowe i bulwiaste - Root and tuber vegetables

\begin{tabular}{|c|c|c|c|c|c|}
\hline Chrzan - Horseradishes & azoxystrobin $^{1}$ & 20 & 1 & 5,0 & 0,2 \\
\hline \multirow{7}{*}{ Marchew - Carrots } & boscalid & 28 & 2 & 7,1 & 0,01 \\
\hline & chlorpyrifos ${ }^{1}$ & 28 & 5 & 17,9 & $0,01-0,04$ \\
\hline & fluopicolide ${ }^{1}$ & 28 & 1 & 3,6 & 0,02 \\
\hline & linuron & 28 & 2 & 7,1 & $0,01-0,02$ \\
\hline & prosulfocarb $^{1}$ & 28 & 1 & 3,6 & 0,01 \\
\hline & picoxystrobin ${ }^{1}$ & 28 & 2 & 7,1 & $0,01-0,05$ \\
\hline & tebuconazole & 28 & 2 & 7,1 & $0,01-0,05$ \\
\hline Pasternak - Parsnips & linuron & 5 & 1 & 20,0 & 0,02 \\
\hline \multirow{9}{*}{$\begin{array}{l}\text { Pietruszka (korzeń) } \\
\text { Parsley root }\end{array}$} & azoxystrobin $^{1}$ & 100 & 9 & 9,0 & $0,005-0,26$ \\
\hline & boscalid & 100 & 12 & 12,0 & $0,007-0,14$ \\
\hline & bupirimate & 100 & 2 & 2,0 & $0,02-0,03$ \\
\hline & chlorpyrifos $^{1}$ & 100 & 8 & 8,0 & $0,01-0,23$ \\
\hline & cypermethrin & 100 & 1 & 1,0 & 0,06 \\
\hline & cyprodinil & 100 & 2 & 2,0 & $0,02-0,04$ \\
\hline & difenoconazole ${ }^{1}$ & 100 & 4 & 4,0 & $0,01-0,28$ \\
\hline & dithiocarbamates & 100 & 3 & 3,0 & $0,07-0,08$ \\
\hline & fludioxonil & 100 & 2 & 2,0 & $0,02-0,05$ \\
\hline
\end{tabular}


Tabela 3. Pozostałości środków ochrony roślin wykryte w poszczególnych produktach - cd.

Table 3. Pesticide residues detected in individual products - continued

\begin{tabular}{|c|c|c|c|c|c|}
\hline 1 & 2 & 3 & 4 & 5 & 6 \\
\hline \multirow{10}{*}{$\begin{array}{l}\text { Pietruszka (korzeń) } \\
\text { Parsley root }\end{array}$} & fluopicolide $^{1}$ & 100 & 1 & 1,0 & 0,01 \\
\hline & fluorochloridone & 100 & 1 & 1,0 & 0,007 \\
\hline & linuron & 100 & 19 & 19,0 & $0,01-0,13$ \\
\hline & mandipropamid $^{1}$ & 100 & 1 & 1,0 & 0,02 \\
\hline & picoxystrobin & 100 & 1 & 1,0 & 0,02 \\
\hline & pirimiphos-methyl $^{1}$ & 100 & 1 & 1,0 & 0,01 \\
\hline & propiconazole $^{1}$ & 100 & 3 & 3,0 & $0,01-0,30$ \\
\hline & pyraclostrobin $^{1}$ & 100 & 2 & 2,0 & $0,01-0,02$ \\
\hline & tebuconazole ${ }^{1}$ & 100 & 4 & 4,0 & $0,02-0,07$ \\
\hline & trifloxystrobin $^{1}$ & 100 & 1 & 1,0 & 0,01 \\
\hline \multirow{9}{*}{ Rzodkiewka - Radish } & azoxystrobin $^{1}$ & 57 & 1 & 1,8 & 0,11 \\
\hline & boscalid & 57 & 6 & 10,5 & $0,01-0,32$ \\
\hline & chlorpyrifos $^{1}$ & 57 & 7 & 12,3 & $0,01-0,40$ \\
\hline & cypermethrin & 57 & 2 & 3,5 & $0,02-0,07$ \\
\hline & diazinon ${ }^{1}$ & 57 & 1 & 1,8 & 0,03 \\
\hline & imidacloprid $^{1}$ & 57 & 1 & 1,8 & 0,04 \\
\hline & iprodione $^{1}$ & 57 & 1 & 1,8 & 0,09 \\
\hline & metalaxyl $^{1}$ & 57 & 1 & 1,8 & 0,05 \\
\hline & pyraclostrobin & 57 & 3 & 5,3 & $0,02-0,04$ \\
\hline \multirow{21}{*}{$\begin{array}{l}\text { Seler korzeniowy } \\
\text { Celeriac }\end{array}$} & azoxystrobin & 100 & 28 & 28,0 & $0,01-0,38$ \\
\hline & bifenthrin ${ }^{1}$ & 100 & 1 & 1,0 & 0,01 \\
\hline & boscalid & 100 & 8 & 8,0 & $0,038-0,27$ \\
\hline & chlorpyrifos $^{1}$ & 100 & 17 & 17,0 & $0,005-0,35$ \\
\hline & chlorpyrifos-methyl ${ }^{1}$ & 100 & 1 & 1,0 & 0,02 \\
\hline & chlorothalonil & 100 & 3 & 3,0 & $0,006-0,02$ \\
\hline & cyprodinil $^{1}$ & 100 & 1 & 1,0 & 0,25 \\
\hline & difenoconazole & 100 & 11 & 11,0 & $0,01-0,16$ \\
\hline & dimethomorph $^{1}$ & 100 & 2 & 2,0 & $0,01-0,02$ \\
\hline & dithiocarbamates & 100 & 1 & 1,0 & 0,08 \\
\hline & fenpropidin ${ }^{1}$ & 100 & 2 & 2,0 & 0,02 \\
\hline & fludioxonil $^{1}$ & 100 & 2 & 2,0 & $0,05-0,13$ \\
\hline & fluorochloridone $^{1}$ & 100 & 2 & 2,0 & $0,02-0,04$ \\
\hline & imidacloprid $^{1}$ & 100 & 1 & 1,0 & 0,03 \\
\hline & iprodione $^{1}$ & 100 & 1 & 1,0 & 0,27 \\
\hline & linuron & 100 & 31 & 31,0 & $0,01-0,32$ \\
\hline & propamocarb $^{1}$ & 100 & 2 & 2,0 & $0,01-0,02$ \\
\hline & propiconazole $^{1}$ & 100 & 6 & 6,0 & $0,01-0,10$ \\
\hline & pyraclostrobin & 100 & 4 & 4,0 & $0,04-0,11$ \\
\hline & tebuconazole ${ }^{1}$ & 100 & 1 & 1,0 & 0,01 \\
\hline & tetraconazole ${ }^{1}$ & 100 & 1 & 1,0 & 0,03 \\
\hline \multicolumn{6}{|c|}{ Warzywa cebulowe - Bulb vegetables } \\
\hline \multirow{2}{*}{ Cebula-Onion } & propamocarb & 44 & 1 & 2,3 & 0,01 \\
\hline & thiamethoxam $^{1}$ & 44 & 1 & 2,3 & 0,01 \\
\hline \multirow{4}{*}{$\begin{array}{l}\text { Dymka/cebula siedmiolatka } \\
\text { i cebula szczypiorowa } \\
\text { Spring onions/green onions } \\
\text { and welsh onions }\end{array}$} & azoxystrobin & 9 & 1 & 11,1 & 1,42 \\
\hline & boscalid & 9 & 1 & 11,1 & 0,17 \\
\hline & chlorpyrifos & 9 & 1 & 11,1 & 0,03 \\
\hline & cypermethrin & 9 & 1 & 11,1 & 0,04 \\
\hline
\end{tabular}


Tabela 3. Pozostałości środków ochrony roślin wykryte w poszczególnych produktach - cd.

Table 3. Pesticide residues detected in individual products - continued

\begin{tabular}{|c|c|c|c|c|c|}
\hline 1 & 2 & 3 & 4 & 5 & 6 \\
\hline \multirow{4}{*}{$\begin{array}{l}\text { Dymka/cebula siedmiolatka } \\
\text { i cebula szczypiorowa } \\
\text { Spring onions/green onions } \\
\text { and welsh onions }\end{array}$} & fluopicolide & 9 & 1 & 11,1 & 0,02 \\
\hline & imidacloprid $^{1}$ & 9 & 1 & 11,1 & 0,11 \\
\hline & metalaxyl & 9 & 1 & 11,1 & 0,01 \\
\hline & pendimethalin & 9 & 1 & 11,1 & 0,01 \\
\hline \multicolumn{6}{|c|}{ Warzywa owocowe - Fruiting vegetables } \\
\hline Bakłażan - Eggplants & iprodione & 6 & 1 & 16,7 & 0,29 \\
\hline \multirow{2}{*}{ Ogórki - Cucumbers } & fluopicolide & 41 & 2 & 4,9 & $0,01-0,02$ \\
\hline & metalaxyl & 41 & 5 & 12,2 & $0,01-0,09$ \\
\hline \multirow{28}{*}{ Pomidory - Tomatoes } & acetamiprid & 105 & 2 & 1,9 & $0,19-0,20$ \\
\hline & azoxystrobin & 105 & 17 & 16,2 & $0,01-0,23$ \\
\hline & benalaxyl & 105 & 1 & 1,0 & 0,03 \\
\hline & boscalid & 105 & 16 & 15,2 & $0,01-0,21$ \\
\hline & buprofezin $^{1}$ & 105 & 1 & 1,0 & 0,11 \\
\hline & chlorpyrifos $^{1}$ & 105 & 1 & 1,0 & 0,11 \\
\hline & chlorothalonil & 105 & 9 & 8,6 & $0,01-0,05$ \\
\hline & cyprodinil & 105 & 11 & 10,5 & $0,02-0,28$ \\
\hline & difenoconazole & 105 & 5 & 4,8 & $0,01-0,30$ \\
\hline & dimethomorph & 105 & 2 & 1,9 & 0,05 \\
\hline & dithiocarbamates & 105 & 8 & 7,6 & $0,07-0,40$ \\
\hline & esfenvalerate ${ }^{1}$ & 105 & 1 & 1,0 & 0,04 \\
\hline & famoxadone & 105 & 10 & 9,5 & $0,01-0,09$ \\
\hline & fenamidone & 105 & 1 & 1,0 & 0,04 \\
\hline & flonicamid $^{1}$ & 105 & 1 & 1,0 & 0,04 \\
\hline & fludioxonil & 105 & 8 & 7,6 & $0,01-0,04$ \\
\hline & fluopicolide $^{1}$ & 105 & 2 & 1,9 & $0,01-0,02$ \\
\hline & iprodione & 105 & 3 & 2,9 & $0,07-0,98$ \\
\hline & mandipropamid & 105 & 1 & 1,0 & 0,02 \\
\hline & metalaxyl & 105 & 1 & 1,0 & 0,03 \\
\hline & pirimiphos-methyl ${ }^{1}$ & 105 & 1 & 1,0 & 0,04 \\
\hline & propiconazole & 105 & 1 & 1,0 & 0,05 \\
\hline & pyraclostrobin & 105 & 5 & 4,8 & $0,02-0,07$ \\
\hline & pyriproxyfen $^{1}$ & 105 & 1 & 1,0 & 0,01 \\
\hline & spiroxamine $^{1}$ & 105 & 1 & 1,0 & 0,02 \\
\hline & tebuconazole ${ }^{1}$ & 105 & 1 & 1,0 & 0,07 \\
\hline & thiophanate-methyl & 105 & 2 & 1,9 & $0,09-0,37$ \\
\hline & triadimenol $^{1}$ & 105 & 1 & 1,0 & 0,03 \\
\hline \multicolumn{6}{|c|}{ Warzywa kapustne - Brassica vegetables } \\
\hline \multirow{5}{*}{ Brokuły - Broccoli } & azoxystrobin & 82 & 1 & 1,2 & 0,07 \\
\hline & chlorpyrifos & 82 & 6 & 7,3 & $0,02-0,12$ \\
\hline & cypermethrin & 82 & 1 & 1,2 & 0,16 \\
\hline & spinosad & 82 & 1 & 1,2 & 0,13 \\
\hline & thiacloprid & 82 & 1 & 1,2 & 0,04 \\
\hline $\begin{array}{l}\text { Kapusta głowiasta } \\
\text { Head cabbage }\end{array}$ & azoxystrobin & 45 & 1 & 2,2 & 0,13 \\
\hline \multirow{3}{*}{$\begin{array}{l}\text { Kapusta brukselska } \\
\text { Brussels sprouts }\end{array}$} & acetamiprid & 24 & 1 & 4,2 & 0,03 \\
\hline & azoxystrobin & 24 & 1 & 4,2 & 0,03 \\
\hline & boscalid & 24 & 1 & 4,2 & 0,04 \\
\hline
\end{tabular}


Tabela 3. Pozostałości środków ochrony roślin wykryte w poszczególnych produktach - cd.

Table 3. Pesticide residues detected in individual products - continued

\begin{tabular}{|c|c|c|c|c|c|}
\hline 1 & 2 & 3 & 4 & 5 & 6 \\
\hline \multirow{4}{*}{$\begin{array}{l}\text { Kapusta brukselska } \\
\text { Brussels sprouts }\end{array}$} & buprofezin $^{1}$ & 24 & 1 & 4,2 & 0,01 \\
\hline & chlorpyrifos & 24 & 4 & 16,7 & $0,01-0,05$ \\
\hline & difenoconazole & 24 & 1 & 4,2 & 0,006 \\
\hline & pirimicarb $^{1}$ & 24 & 1 & 4,2 & 0,01 \\
\hline \multirow{24}{*}{$\begin{array}{l}\text { Kapusta pekińska } \\
\text { Chinese cabbage }\end{array}$} & alpha-cypermethrin ${ }^{1}$ & 132 & 1 & 0,8 & 0,04 \\
\hline & azoxystrobin & 132 & 14 & 10,6 & $0,006-0,23$ \\
\hline & bifenthrin ${ }^{1}$ & 132 & 3 & 2,3 & $0,04-0,10$ \\
\hline & boscalid $^{1}$ & 132 & 5 & 3,8 & $0,06-0,44$ \\
\hline & carbendazim $^{1}$ & 132 & 1 & 0,8 & 0,03 \\
\hline & chlorothalonil $1^{1}$ & 132 & 2 & 1,5 & $0,05-0,09$ \\
\hline & chlorpyrifos $^{1}$ & 132 & 25 & 18,9 & $0,006-1,30$ \\
\hline & cypermethrin $^{1}$ & 132 & 4 & 3,0 & $0,02-0,12$ \\
\hline & deltamethrin & 132 & 1 & 0,8 & 0,02 \\
\hline & difenoconazole & 132 & 3 & 2,3 & 0,02 \\
\hline & dimethoate ${ }^{1}$ & 132 & 1 & 0,8 & 0,04 \\
\hline & esfenvalerate ${ }^{1}$ & 132 & 3 & 2,3 & $0,03-0,15$ \\
\hline & flutriafol $^{1}$ & 132 & 1 & 0,8 & 0,06 \\
\hline & indoxacarb $^{1}$ & 132 & 1 & 0,8 & 0,02 \\
\hline & iprodione & 132 & 5 & 3,8 & $0,04-0,10$ \\
\hline & lambda-cyhalothrin ${ }^{1}$ & 132 & 2 & 1,5 & $0,02-0,04$ \\
\hline & metalaxyl & 132 & 1 & 0,8 & 0,06 \\
\hline & pirimicarb $^{1}$ & 132 & 2 & 1,5 & $0,03-0,04$ \\
\hline & pirimiphos-methyl & 132 & 1 & 0,8 & 0,12 \\
\hline & pyrimethanil $^{1}$ & 132 & 2 & 1,5 & 0,04 \\
\hline & pyraclostrobin & 132 & 1 & 0,8 & 0,21 \\
\hline & tebuconazole ${ }^{1}$ & 132 & 1 & 0,8 & 0,07 \\
\hline & thiophanate-methyl ${ }^{1}$ & 132 & 1 & 0,8 & 0,09 \\
\hline & trifloxystrobin ${ }^{1}$ & 132 & 4 & 3,0 & $0,01-3,91$ \\
\hline Rukola - Rucola & chlorpyrifos $^{1}$ & 5 & 1 & 20,0 & 0,03 \\
\hline \multicolumn{6}{|c|}{ Warzywa liściowe i świeże zioła - Leaf vegetables and fresh herbs } \\
\hline \multirow{14}{*}{ Koper - Dill } & azoxystrobin $^{1}$ & 82 & 2 & 2,4 & $0,008-0,15$ \\
\hline & bifenthrin ${ }^{1}$ & 82 & 1 & 1,2 & 0,01 \\
\hline & boscalid & 82 & 3 & 3,7 & $0,09-1,10$ \\
\hline & chlorpyrifos ${ }^{1}$ & 82 & 21 & 25,6 & $0,01-0,66$ \\
\hline & chlorothalonil $^{1}$ & 82 & 1 & 1,2 & 0,05 \\
\hline & deltamethrin ${ }^{1}$ & 82 & 1 & 1,2 & 0,17 \\
\hline & dithiocarbamates ${ }^{1}$ & 82 & 1 & 1,2 & 0,07 \\
\hline & esfenvalerate ${ }^{1}$ & 82 & 1 & 1,2 & 0,03 \\
\hline & iprodione & 82 & 1 & 1,2 & 0,10 \\
\hline & lambda-cyhalothrin ${ }^{1}$ & 82 & 1 & 1,2 & 0,24 \\
\hline & metalaxyl $^{1}$ & 82 & 1 & 1,2 & 0,04 \\
\hline & pendimethalin ${ }^{1}$ & 82 & 16 & 19,5 & $0,02-0,88$ \\
\hline & pirimicarb & 82 & 1 & 1,2 & 0,04 \\
\hline & pyrimethanil $^{1}$ & 82 & 2 & 2,4 & $0,06-0,11$ \\
\hline \multirow{3}{*}{ Sałata - Lettuce } & azoxystrobin & 64 & 6 & 9,4 & $0,02-2,70$ \\
\hline & bifenthrin ${ }^{1}$ & 64 & 1 & 1,6 & 2,30 \\
\hline & boscalid & 64 & 1 & 1,6 & 0,13 \\
\hline
\end{tabular}


Tabela 3. Pozostałości środków ochrony roślin wykryte w poszczególnych produktach - cd.

Table 3. Pesticide residues detected in individual products - continued

\begin{tabular}{|c|c|c|c|c|c|}
\hline 1 & 2 & 3 & 4 & 5 & 6 \\
\hline \multirow{10}{*}{ Sałata-Lettuce } & chlorpyrifos $^{1}$ & 64 & 2 & 3,1 & $0,04-0,15$ \\
\hline & chlorpyrifos-methyl ${ }^{1}$ & 64 & 1 & 1,6 & 0,06 \\
\hline & cyprodinil & 64 & 1 & 1,6 & 0,03 \\
\hline & deltamethrin & 64 & 1 & 1,6 & 0,012 \\
\hline & dithiocarbamates & 64 & 6 & 9,4 & $0,04-3,48$ \\
\hline & esfenvalerate ${ }^{1}$ & 64 & 1 & 1,6 & 0,15 \\
\hline & fenhexamid $^{1}$ & 64 & 1 & 1,6 & 1,80 \\
\hline & fenvalerate $^{1}$ & 64 & 1 & 1,6 & 0,24 \\
\hline & iprodione & 64 & 1 & 1,6 & 1,86 \\
\hline & lambda-cyhalothrin ${ }^{1}$ & 64 & 1 & 1,6 & 0,40 \\
\hline \multirow{2}{*}{ Szczypiorek - Chives } & azoxystrobin & 10 & 1 & 10,0 & 0,04 \\
\hline & chlorpyrifos $^{1}$ & 10 & 1 & 10,0 & 0,01 \\
\hline \multirow{10}{*}{ Szpinak - Spinaches } & acetamiprid & 45 & 3 & 6,7 & $0,03-0,90$ \\
\hline & azoxystrobin ${ }^{1}$ & 45 & 2 & 4,4 & $0,05-0,09$ \\
\hline & boscalid & 45 & 3 & 6,7 & $0,04-0,57$ \\
\hline & chlorpyrifos $^{1}$ & 45 & 4 & 8,9 & $0,01-0,21$ \\
\hline & dithiocarbamates & 45 & 3 & 6,7 & $0,06-1,40$ \\
\hline & esfenvalerate & 45 & 1 & 2,2 & 0,05 \\
\hline & fenvalerate & 45 & 1 & 2,2 & 0,06 \\
\hline & iprodione $^{1}$ & 45 & 1 & 2,2 & 0,36 \\
\hline & lambda-cyhalothrin ${ }^{1}$ & 45 & 1 & 2,2 & 0,11 \\
\hline & linuron $^{1}$ & 45 & 1 & 2,2 & 0,02 \\
\hline \multicolumn{6}{|c|}{ Warzywa strączkowe - Legume vegetables } \\
\hline $\begin{array}{l}\text { Fasola szparagowa } \\
\text { String bean }\end{array}$ & boscalid $^{1}$ & 29 & 1 & 3,4 & 0,07 \\
\hline \multirow{2}{*}{$\begin{array}{l}\text { Groszek zielony - Green } \\
\text { pea }\end{array}$} & azoxystrobin & 19 & 2 & 10,5 & 0,02 \\
\hline & linuron & 19 & 1 & 5,3 & 0,02 \\
\hline \multicolumn{6}{|c|}{ Warzywa łodygowe - Stem vegetables } \\
\hline Por - Leek & metribuzin $^{1}$ & 25 & 1 & 4,0 & 0,02 \\
\hline Szparagi-Asparagus & dithiocarbamates & 8 & 1 & 12,5 & 0,06 \\
\hline \multicolumn{6}{|c|}{ Nasiona oleiste - Oilseeds } \\
\hline \multirow{6}{*}{ Rzepak - Rapeseed } & carbendazim & 84 & 1 & 1,2 & 0,06 \\
\hline & flutriafol & 84 & 2 & 2,4 & $0,02-0,04$ \\
\hline & pirimiphos-methyl & 84 & 3 & 3,6 & $0,04-0,05$ \\
\hline & tebuconazole & 84 & 10 & 11,9 & $0,01-0,05$ \\
\hline & tetraconazole & 84 & 3 & 3,6 & 0,01 \\
\hline & thiacloprid & 84 & 1 & 1,2 & 0,01 \\
\hline \multicolumn{6}{|c|}{ Zboża-Cereals } \\
\hline \multirow{3}{*}{ Gryka-Buckwheat } & carbaryl $^{1}$ & 22 & 1 & 4,5 & 0,01 \\
\hline & clothianidin ${ }^{1}$ & 22 & 1 & 4,5 & 0,02 \\
\hline & pirimiphos-methyl & 22 & 1 & 4,5 & 0,01 \\
\hline \multirow{6}{*}{ Jęczmień - Barley } & azoxystrobin & 81 & 1 & 1,2 & 0,03 \\
\hline & carbendazim & 81 & 2 & 2,5 & $0,04-0,22$ \\
\hline & cypermethrin & 81 & 1 & 1,2 & 0,10 \\
\hline & cyproconazole & 81 & 1 & 1,2 & 0,02 \\
\hline & cyprodinil & 81 & 1 & 1,2 & 0,01 \\
\hline & dimethoate $^{1}$ & 81 & 1 & 1,2 & 0,04 \\
\hline
\end{tabular}


Tabela 3. Pozostałości środków ochrony roślin wykryte w poszczególnych produktach - cd.

Table 3. Pesticide residues detected in individual products - continued

\begin{tabular}{|c|c|c|c|c|c|}
\hline 1 & 2 & 3 & 4 & 5 & 6 \\
\hline \multirow{6}{*}{ Jęczmień - Barley } & epoxiconazole & 81 & 1 & 1,2 & 0,05 \\
\hline & picoxystrobin & 81 & 2 & 2,5 & $0,01-0,02$ \\
\hline & pirimiphos-methyl & 81 & 10 & 12,3 & $0,01-0,67$ \\
\hline & propiconazole & 81 & 1 & 1,2 & 0,01 \\
\hline & tebuconazole & 81 & 4 & 4,9 & $0,01-0,03$ \\
\hline & triticonazole & 81 & 2 & 2,5 & $0,07-0,21$ \\
\hline Kukurydza - Corn & pirimiphos-methyl $^{1}$ & 65 & 4 & 6,2 & $0,006-0,56$ \\
\hline \multirow{2}{*}{$\begin{array}{l}\text { Mieszanka zbożowa } \\
\text { Cereal mix }\end{array}$} & pirimiphos-methyl & 66 & 1 & 1,5 & 0,08 \\
\hline & tebuconazole & 66 & 1 & 1,5 & 0,01 \\
\hline Owies - Oat & pirimiphos-methyl & 31 & 1 & 3,2 & 0,03 \\
\hline \multirow{4}{*}{ Proso - Common millet } & acetamiprid $^{1}$ & 20 & 1 & 5,0 & 0,26 \\
\hline & chlorpyrifos $^{1}$ & 20 & 1 & 5,0 & 0,99 \\
\hline & deltamethrin ${ }^{1}$ & 20 & 1 & 5,0 & 0,10 \\
\hline & pirimiphos-methyl $^{1}$ & 20 & 2 & 10,0 & $0,10-0,95$ \\
\hline \multirow{13}{*}{ Pszenica - Wheat } & azoxystrobin & 311 & 2 & 0,6 & $0,01-0,05$ \\
\hline & carbendazim & 311 & 4 & 1,3 & $0,01-0,10$ \\
\hline & chlorpyrifos & 311 & 2 & 0,6 & $0,01-0,09$ \\
\hline & cyproconazole & 311 & 1 & 0,3 & 0,01 \\
\hline & dimethoate & 311 & 1 & 0,3 & 0,13 \\
\hline & dimoxystrobin & 311 & 2 & 0,6 & $0,01-0,02$ \\
\hline & epoxiconazole & 311 & 2 & 0,6 & $0,01-0,02$ \\
\hline & imidacloprid & 311 & 1 & 0,3 & 0,02 \\
\hline & pencycuron $^{1}$ & 311 & 1 & 0,3 & 0,06 \\
\hline & pirimiphos-methyl & 311 & 25 & 8,0 & $0,005-0,332$ \\
\hline & prochloraz & 311 & 2 & 0,6 & $0,01-0,04$ \\
\hline & tebuconazole & 311 & 29 & 9,3 & $0,01-0,14$ \\
\hline & tetraconazole & 311 & 2 & 0,6 & $0,01-0,02$ \\
\hline \multirow{5}{*}{ Pszenżyto - Triticale } & carbendazim & 90 & 2 & 2,2 & $0,04-0,06$ \\
\hline & deltamethrin & 90 & 1 & 1,1 & 0,27 \\
\hline & pirimiphos-methyl & 90 & 10 & 11,1 & $0,02-0,13$ \\
\hline & propiconazole & 90 & 1 & 1,1 & 0,02 \\
\hline & tebuconazole & 90 & 4 & 4,4 & 0,01 \\
\hline \multirow{4}{*}{ Żyto - Rye } & carbendazim & 74 & 1 & 1,4 & 0,04 \\
\hline & chlorpyrifos $^{1}$ & 74 & 1 & 1,4 & 0,01 \\
\hline & epoxiconazole & 74 & 1 & 1,4 & 0,01 \\
\hline & pirimiphos-methyl & 74 & 8 & 10,8 & $0,008-0,082$ \\
\hline \multicolumn{6}{|c|}{ Rośliny cukrodajne - Sugar plants } \\
\hline $\begin{array}{l}\text { Burak cukrowy } \\
\text { Sugar beet root }\end{array}$ & epoxiconazole & 32 & 6 & 18,8 & $0,01-0,07$ \\
\hline \multicolumn{6}{|c|}{ Przyprawy - Spices } \\
\hline \multirow{5}{*}{ Kminek - Black caraway } & chlorpyrifos $^{1}$ & 8 & 2 & 25,0 & $0,01-0,05$ \\
\hline & linuron & 8 & 1 & 12,5 & 0,07 \\
\hline & metalaxyl $^{1}$ & 8 & 1 & 12,5 & 0,02 \\
\hline & pirimiphos-methyl $1^{1}$ & 8 & 2 & 25,0 & $0,02-1,35$ \\
\hline & thiacloprid $^{1}$ & 8 & 1 & 12,5 & 0,04 \\
\hline
\end{tabular}

${ }^{1}$ substancja czynna niepoduszczona do ochrony danej uprawy - active substance not authorised for protection of given crop 
Tabela 4. Produkty, w których stwierdzono przekroczenia najwyższych dopuszczalnych poziomów pozostałości Table 4. Products with residues exceeding maximum residue levels

\begin{tabular}{|c|c|c|c|c|c|c|}
\hline \multirow{2}{*}{$\begin{array}{l}\text { Produkt } \\
\text { Product }\end{array}$} & \multirow{2}{*}{$\begin{array}{c}\text { Związek } \\
\text { Compound }\end{array}$} & \multirow{2}{*}{\begin{tabular}{|} 
Liczba badanych \\
próbek \\
Number of \\
analysed samples
\end{tabular}} & \multicolumn{2}{|c|}{$\begin{array}{l}\text { Przekroczenia NDP } \\
\text { MRLs exceedances }\end{array}$} & \multirow{2}{*}{\begin{tabular}{|c|} 
Poziom \\
pozostałości \\
Residue level \\
{$[\mathrm{mg} / \mathrm{kg}]$}
\end{tabular}} & \multirow{2}{*}{$\begin{array}{r}\mathrm{NDP}^{1} \\
\mathrm{MRLs} \\
{[\mathrm{mg} / \mathrm{kg}}\end{array}$} \\
\hline & & & $\begin{array}{l}\text { liczba } \\
\text { number }\end{array}$ & $\begin{array}{l}\text { procent } \\
\text { percent }\end{array}$ & & \\
\hline Agrest - Gooseberries & propiconazole $^{2}$ & 20 & 1 & 5,0 & 0,14 & 0,05 \\
\hline Brokuły - Broccoli & chlorpyrifos & 82 & 1 & 1,2 & 0,12 & 0,05 \\
\hline Jęczmień - Barley & triticonazole & 81 & 1 & 1,2 & 0,21 & 0,01 \\
\hline Kapusta pekińska - Chinese cabbage & chlorothalonil $^{2}$ & 132 & 2 & 1,5 & $\begin{array}{l}0,05 \\
0,09\end{array}$ & 0,01 \\
\hline Kapusta pekińska - Chinese cabbage & pyrimethanil $^{2}$ & 132 & 2 & 1,5 & 0,04 & 0,01 \\
\hline Kapusta pekińska - Chinese cabbage & chlorpyrifos $^{2}$ & 132 & 1 & 0,8 & 1,30 & 0,5 \\
\hline \multirow{2}{*}{ Kapusta pekińska - Chinese cabbage } & esfenvalerate $^{2}$ & \multirow{2}{*}{132} & \multirow{2}{*}{1} & \multirow{2}{*}{0,8} & 0,11 & 0,02 \\
\hline & tebuconazole $^{2}$ & & & & 0,07 & 0,02 \\
\hline Kapusta pekińska - Chinese cabbage & esfenvalerate $^{2}$ & 132 & 1 & 0,8 & 0,15 & 0,02 \\
\hline Koper - Dill & pendimethalin $^{2}$ & 82 & 3 & 3,7 & $\begin{array}{l}0,42 \\
0,88 \\
0,18 \\
\end{array}$ & 0,05 \\
\hline \multirow{2}{*}{ Koper - Dill } & lambda-cyhalothrin ${ }^{2}$ & \multirow{2}{*}{82} & \multirow{2}{*}{1} & \multirow{2}{*}{1,2} & 0,24 & 0,05 \\
\hline & pendimethalin $^{2}$ & & & & 0,11 & 0,05 \\
\hline Koper-Dill & chlorpyrifos $^{2}$ & 82 & 4 & 4,9 & $\begin{array}{l}0,40 \\
0,24 \\
0,66 \\
0,20 \\
\end{array}$ & 0,05 \\
\hline Maliny - Raspberries & fenazaquin $^{2}$ & 111 & 1 & 0,9 & 0,06 & 0,01 \\
\hline Maliny - Raspberries & spirodiclofen $^{2}$ & 111 & 1 & 0,9 & 0,07 & 0,02 \\
\hline \multirow{3}{*}{ Maliny - Raspberries } & flutriafol $^{2}$ & \multirow{3}{*}{111} & \multirow{3}{*}{1} & \multirow{3}{*}{0,9} & 0,14 & 0,05 \\
\hline & penconazole $^{2}$ & & & & 0,35 & 0,05 \\
\hline & spirodiclofen $^{2}$ & & & & 0,08 & 0,02 \\
\hline Marchew - Carrots & picoxystrobin $^{2}$ & 28 & 1 & 3,6 & 0,05 & 0,01 \\
\hline Pietruszka (korzeń) - Parsley root & chlorpyrifos $^{2}$ & 100 & 1 & 1,0 & 0,23 & 0,05 \\
\hline \multirow{2}{*}{ Porzeczki - Currants } & cypermethrin & \multirow{2}{*}{82} & \multirow{2}{*}{1} & \multirow{2}{*}{1,2} & 0,30 & 0,05 \\
\hline & thiophanate-methyl ${ }^{2}$ & & & & 0,65 & 0,1 \\
\hline \multirow{2}{*}{ Proso - Common millet } & acetamiprid $^{2}$ & \multirow{2}{*}{20} & \multirow{2}{*}{1} & \multirow{2}{*}{5,0} & 0,26 & 0,01 \\
\hline & chlorpyrifos $^{2}$ & & & & 0,99 & 0,05 \\
\hline Pszenica - Wheat & dimethoate & 311 & 1 & 0,3 & 0,13 & 0,05 \\
\hline Sałata-Lettuce & chlorpyrifos $^{2}$ & 64 & 1 & 1,6 & 0,15 & 0,05 \\
\hline Sałata - Lettuce & $\begin{array}{l}\text { fenvalerate and } \\
\text { esfenvalerate (sum) })^{2}\end{array}$ & 64 & 1 & 1,6 & 0,39 & 0,02 \\
\hline Seler korzeniowy - Celeriac & chlorpyrifos $^{2}$ & 100 & 2 & 2,0 & $\begin{array}{l}0,18 \\
0,35 \\
\end{array}$ & 0,05 \\
\hline Seler korzeniowy - Celeriac & iprodione $^{2}$ & 100 & 1 & 1,0 & 0,27 & 0,01 \\
\hline Szpinak - Spinaches & chlorpyrifos $^{2}$ & 45 & 1 & 2,2 & 0,21 & 0,2 \\
\hline Szpinak - Spinaches & dithiocarbamates & 45 & 1 & 2,2 & 1,40 & 0,05 \\
\hline Szpinak - Spinaches & $\begin{array}{l}\text { fenvalerate and } \\
\text { esfenvalerate (sum) }\end{array}$ & 45 & 1 & 2,2 & 0,11 & 0,02 \\
\hline Szpinak - Spinaches & iprodione $^{2}$ & 45 & 1 & 2,2 & 0,36 & 0,02 \\
\hline Truskawki - Strawberries & folpet $^{2}$ & 64 & 1 & 1,6 & 0,15 & 0,05 \\
\hline Winogrona - Grapes & captan $^{2}$ & 26 & 1 & 3,8 & 0,61 & 0,02 \\
\hline Ogółem - Overall & & 2699 & 37 & 1,4 & - & - \\
\hline
\end{tabular}

${ }^{1}$ najwyższe dopuszczalne poziomy pozostałości - Maximum Residue Levels

${ }^{2}$ niedopuszczona substancja aktywna - unauthorised active substance 


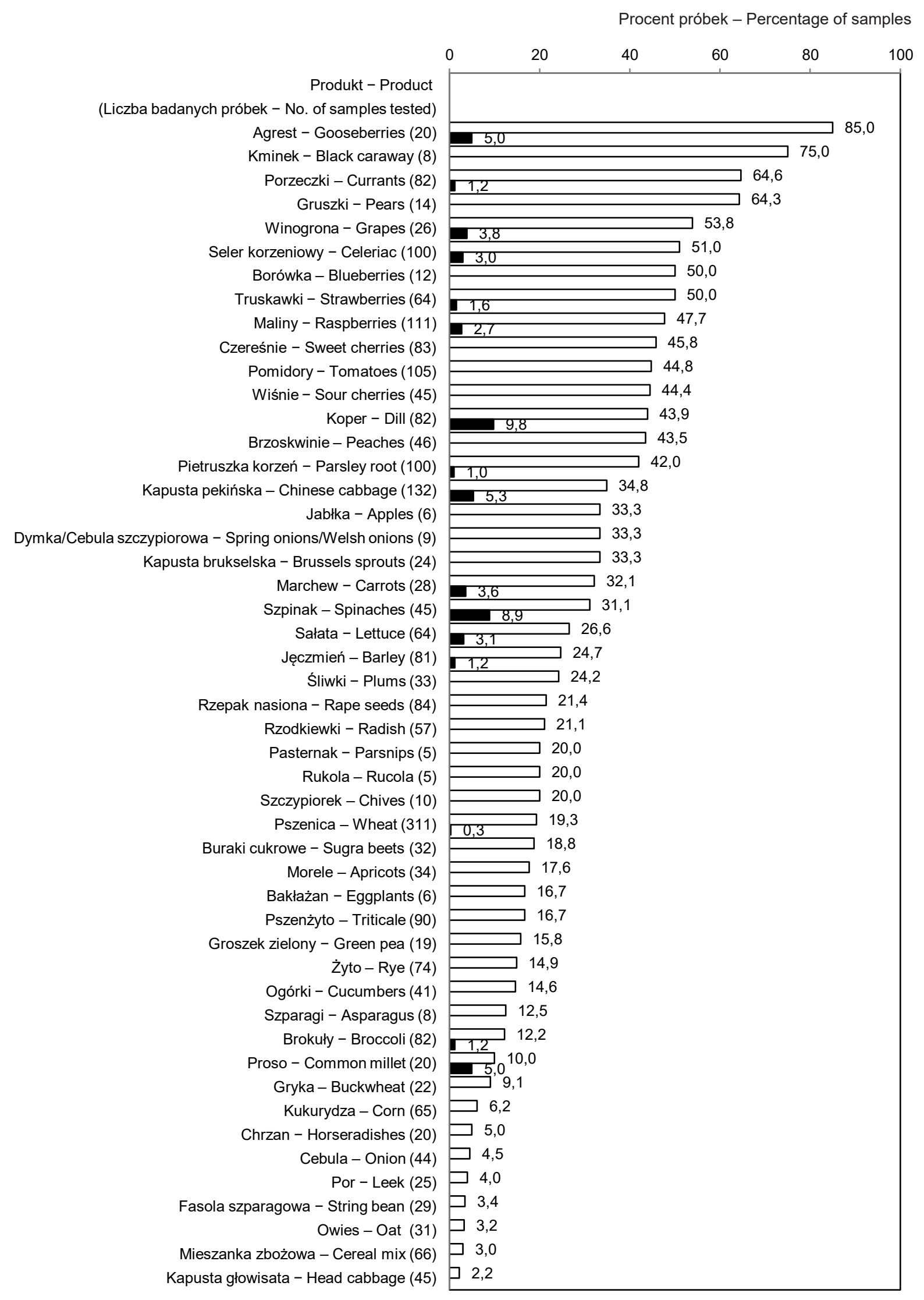

口Próbki z pozostałościami - Samples with residues

- Próbki z pozostałościami > NDP - Samples with residues > MRLs

Rys. 3. Częstotliwość występowania pozostałości środków ochrony roślin w poszczególnych produktach (2014-2015)

Fig. 3. The frequency of pesticide residue occurrence in individual products (2014-2015) 
Procent próbek - Percentage of samples

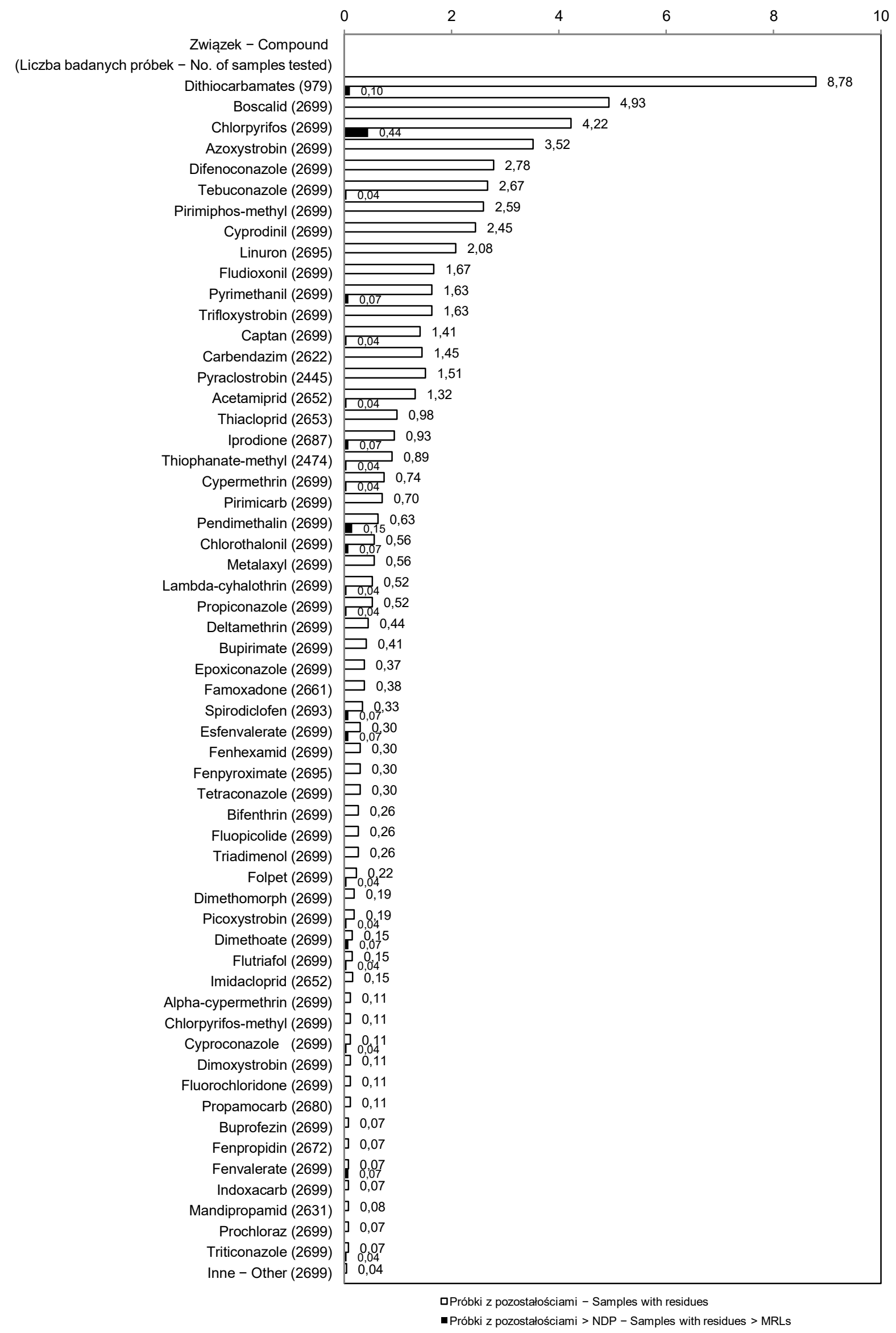

Rys. 4. Częstotliwość wykrywania poszczególnych związków (2014-2015)

Fig. 4. The frequency of occurrence of the compounds detected (2014-2015) 
Tabela 5. Produkty z pozostałościami środków niedopuszczonych

Table 5. Products with residues of unauthorised plant protection products

\begin{tabular}{|c|c|c|c|c|}
\hline \multirow[t]{2}{*}{$\begin{array}{l}\text { Produkt } \\
\text { Product }\end{array}$} & \multirow{2}{*}{$\begin{array}{l}\text { Liczba badanych } \\
\text { próbek } \\
\text { Number of analysed } \\
\text { samples }\end{array}$} & \multicolumn{2}{|c|}{$\begin{array}{l}\text { Próbki z pozostałościami związków } \\
\text { niedopuszczonych } \\
\text { Samples with residues of unapproved } \\
\text { compounds }\end{array}$} & \multirow{2}{*}{$\begin{array}{c}\text { Liczba } \\
\text { niedopuszczonych } \\
\text { związków } \\
\text { Number of unapproved } \\
\text { compounds }\end{array}$} \\
\hline & & $\begin{array}{l}\text { liczba } \\
\text { number }\end{array}$ & $\begin{array}{l}\text { procent } \\
\text { percent }\end{array}$ & \\
\hline Agrest - Gooseberries & 20 & 7 & 35,0 & 12 \\
\hline Brzoskwinie - Peaches & 46 & 12 & 26,1 & 6 \\
\hline Cebula-Onion & 44 & 1 & 2,3 & 1 \\
\hline Cebula szczypiorowa - Welsh onions & 9 & 1 & 11,1 & 1 \\
\hline Chrzan - Horseradishes & 20 & 1 & 5,0 & 1 \\
\hline Czereśnie - Sweet cherries & 83 & 16 & 19,3 & 7 \\
\hline Fasola szparagowa - String bean & 29 & 1 & 3,4 & 1 \\
\hline Gruszki - Pears & 14 & 2 & 14,3 & 1 \\
\hline Gryka-Buckwheat & 22 & 1 & 4,5 & 2 \\
\hline Jęczmień - Barley & 81 & 1 & 1,2 & 1 \\
\hline Kapusta brukselska - Brussels sprouts & 24 & 2 & 8,3 & 2 \\
\hline Kapusta pekińska - Chinese cabbage & 132 & 35 & 26,5 & 17 \\
\hline Kminek - Black caraway & 8 & 5 & 62,5 & 4 \\
\hline Koper-Dill & 82 & 33 & 40,2 & 11 \\
\hline Kukurydza - Corn & 65 & 1 & 1,5 & 1 \\
\hline Maliny - Raspberries & 111 & 4 & 3,6 & 6 \\
\hline Marchew - Carrots & 28 & 8 & 28,6 & 4 \\
\hline Morele-Apricots & 34 & 5 & 14,7 & 2 \\
\hline Pietruszka (korzeń) - Parsley root & 100 & 19 & 19,0 & 10 \\
\hline Pomidory - Tomatoes & 105 & 4 & 3,8 & 10 \\
\hline Por - Leek & 25 & 1 & 4,0 & 1 \\
\hline Porzeczki - Currants & 82 & 4 & 4,9 & 5 \\
\hline Proso - Common millet & 20 & 1 & 5,0 & 4 \\
\hline Pszenica - Wheat & 311 & 1 & 0,3 & 1 \\
\hline Rukola - Rucola & 5 & 1 & 20,0 & 1 \\
\hline Rzodkiewka - Radish & 57 & 10 & 17,5 & 6 \\
\hline Sałata - Lettuce & 64 & 6 & 9,4 & 6 \\
\hline Seler korzeniowy - Celeriac & 100 & 27 & 27,0 & 13 \\
\hline Szczypiorek - Chives & 10 & 1 & 10,0 & 1 \\
\hline Szpinak - Spinaches & 45 & 7 & 15,6 & 5 \\
\hline Truskawki - Strawberries & 64 & 4 & 6,3 & 2 \\
\hline Winogrona - Grapes & 26 & 5 & 19,2 & 10 \\
\hline Wiśnie - Sour cherries & 45 & 2 & 4,4 & 3 \\
\hline Żyto - Rye & 74 & 1 & 1,4 & 1 \\
\hline Ogółem - Overall & 2699 & 230 & 8,5 & 66 \\
\hline Warzywa - Vegetables & 1167 & 158 & 13,5 & - \\
\hline Owoce - Fruits & 612 & 61 & 10,0 & - \\
\hline Zboża-Cereals & 760 & 6 & 0,8 & - \\
\hline Przyprawy - Spices & 8 & 5 & 62,5 & - \\
\hline
\end{tabular}


częstości wykrywania w stosunku do stwierdzonej w 2013 roku, stanowiącej wówczas 32,4\% (Nowacka i wsp. 2015), należy przypisać wyraźnemu zwiększeniu udziału próbek zbóż w badaniach, zawierających rzadziej pozostałości niż warzywa i owoce. W odniesieniu do 2013 roku, odsetek próbek owoców z pozostałościami ś.o.r. spadł, a warzyw wzrósł, gdyż wtedy wynosił odpowiednio 46,5\% i 21,4\% (Nowacka i wsp. 2015), ale różnice są nieznaczne.

Procent próbek płodów rolnych niespełniających wymagań był porównywalny ze stwierdzonym w badaniach wykonanych w Unii Europejskiej, czy w Stanach Zjednoczonych, na co wskazują dane statystyczne pochodzące z monitoringów żywności przeprowadzonych w latach 2014-2015. Według raportów opracowanych przez Europejski Urząd ds. Bezpieczeństwa Żywności (EFSA), odsetek żywności niespełniającej wymagań badanych $\mathrm{w}$ ramach skoordynowanego monitoringu unijnego, obejmującego kilkanaście wybranych produktów, był wyjątkowo niski, bo wynosił odpowiednio 0,8 i 0,4\% w 2014 i 2015 roku, ale wyznaczony na podstawie monitoringów krajowych państw członkowskich, obejmujących szeroką gamę produktów, był wyższy i stanowił w obu latach 1,6\% (Scientific Report 2016, 2017). Raporty Amerykańskiej Agencji Żywności i Leków (FDA) podają podobne wskaźniki dla przekroczeń tolerancji w żywności wyprodukowanej w USA w tym okresie - 1,4 i 1,8\% (Pesticide 2017a, b). Porównując uzyskane wyniki do wspominanych statystyk zagranicznych $\mathrm{z}$ tego samego okresu można stwierdzić, że rodzime produkty rolne w mniejszym stopniu były zanieczyszczone pozostałościami ś.o.r. niż żywność w obrocie unijnym (46,4 i 46,7\%), czy też amerykańska (50,2 i 29,1\%) (Scientific Report 2016, 2017; Pesticide 2017a, b).

Prowadzona przez Państwową Inspekcję Ochrony Roślin i Nasiennictwa urzędowa kontrola pozostałości ś.o.r. w płodach rolnych na etapie produkcji pierwotnej jest losowa, ale jednocześnie ukierunkowana, na podstawie dotychczasowych doświadczeń, na obszary potencjalnych zagrożeń (przekroczenia NDP, stosowanie środków niedozwolonych). Kontrola pozwoliła na identyfikowanie problemów związanych ze stosowaniem środków i uruchamianie działań zmierzających do ograniczenia ich występowania (edukacja producentów, nakładanie kar). Niestety, zmieniające się regulacje, w tym głównie decyzje o wycofaniu preparatów lub ograniczeniu ich stosowania, wpływają na zwiększenie liczby naruszeń, ponieważ proces dostosowywania się producentów rolnych do nowych uregulowań trwa znacznie dłużej, niż to zakładają przepisy.

Badania stanowiły dla Ministerstwa Rolnictwa i Rozwoju Wsi także cenne źródło wiedzy o rodzaju i poziomach występujących pozostałości ś.o.r. w polskich płodach rolnych $\mathrm{i}$ informowały o skuteczności przepisów regulujących warunki i sposoby stosowania ś.o.r. w praktyce rolniczej.
Badania umożliwiły oszacowanie długo- i krótkoterminowego narażenia ludzi na pozostałości ś.o.r., co pozwoliło na ocenę ryzyka zdrowotnego związanego $\mathrm{z}$ ich pobraniem z żywnością.

\section{Wnioski / Conclusions}

1. Prawie wszystkie krajowe płody rolne $(98,6 \%)$ spełniały wymagania prawa żywnościowego dotyczące najwyższych dopuszczalnych poziomów pozostałości ś.o.r.

2. Pozostałości ś.o.r. wykrywano głównie w owocach $(45,4 \%)$ i przyprawach $(75,0 \%)$, rzadziej w warzywach (27,1\%), ziarnie zbóż $(15,4 \%)$ i rzepaku $(21,4 \%)$ oraz burakach cukrowych (18,8\%).

3. Spośród 368 badanych substancji czynnych ś.o.r. stwierdzono 77, najwięcej fungicydów - 40, nieco mniej insektycydów i akarycydów - 31 i niewiele herbicydów - 6 .

4. Skala przekroczeń najwyższych dopuszczalnych poziomów pozostałości była niewielka $(1,4 \%)$, stanowiły one zjawisko marginalne.

5. Obecność pozostałości środków niedopuszczonych do stosowania stwierdzono w $8,5 \%$ badanych próbek, przeważnie warzyw (13,5\%), owoców $(10,0 \%)$ i przypraw (62,5\%), sporadycznie zbóż $(0,8 \%)$, co można przypisać brakowi wystarczającego asortymentu środków do ochrony upraw małoobszarowych.

6. Wyniki badań wykonywanych w ramach urzędowej kontroli prowadzonej przez Państwową Inspekcję Ochrony Roślin i Nasiennictwa potwierdzają skuteczność i konieczność stałego nadzoru nad stosowaniem ś.o.r., jak również ich istotną rolę $\mathrm{w}$ identyfikowaniu pojawiających się zagrożeń w tym obszarze.

\section{Podziękowanie / Acknowledgements}

Wyrazy podziękowania dla obecnych i byłych pracowników IOR - PIB uczestniczących w badaniach pozostałości ś.o.r. w latach 2014-2015 realizowanych w ramach programu wieloletniego na lata 2011-2015 „Ochrona roślin uprawnych z uwzględnieniem bezpieczeństwa żywności oraz ograniczenia strat w plonach i zagrożeń dla zdrowia ludzi, zwierząt domowych i środowiska": Doroty Gawrońskiej, Marty Zdziechowskiej, Andrzeja Ziółkowskiego, Alicji Małeckiej, Anny Wesołowskiej, Urszuli Zeller, Izabeli Domańskiej, Urszuli Rzeszutko, Ewy Rutkowskiej, Magdaleny Jankowskiej, Izabeli Hrynko, Ewy Szpyrki, Juliana Rupara, Anety Matyaszek, Anny Kurdziel, Magdaleny Podbielskiej i Magdaleny Słowik-Borowiec. 


\section{Literatura / References}

Chmiel Z. 1979. Spektrofotometryczne oznaczanie śladowych pozostałości dwutiokarbaminianów w materiale roślinnym. Chemia Analityczna 24: 505-511.

Decyzja wykonawcza Komisji z dnia 17 listopada 2014 r. dotycząca zmiany programu prac na rok 2014 objętego decyzją wykonawczą Komisji 2014/C 166/05 oraz przyjęcia programu prac i finansowania działań w zakresie żywności i paszy na rok 2015 w celu zapewnienia stosowania prawodawstwa dotyczącego żywności i paszy. 2014. Dz. U. C 410 z 18.11.2014 r., s. 3-9.

Dyrektywa Parlamentu Europejskiego i Rady 2009/128/WE z dnia 21 października 2009 r. ustanawiającej ramy wspólnotowego działania na rzecz zrównoważonego stosowania pestycydów. 2009. Dz. Urz. L 309 z 24.11.2009 r., s. 71.

Guidance document on analytical quality control and validation procedures for pesticide residues analysis in food and feed. 2013. Document No. SANCO/12571/2013. Supersedes Document No. SANCO/12495/2011. Implemented by 01/01/2014.

Norma PN-EN 15662:2008. 2008. Żywność pochodzenia roślinnego - Oznaczanie pozostałości pestycydów metodą GC-MS i/lub LC-MS(/MS) po uprzedniej ekstrakcji i rozdziale acetonitrylem oraz oczyszczaniu metodą dyspersyjnej SPE - Metoda QuEChERS.

Norma PN-EN ISO/IEC 17025:2005. 2005. Ogólne wymagania dotyczące kompetencji laboratoriów badawczych i wzorcujących.

Nowacka A., Gnusowski B., Walorczyk S., Drożdżyński D., Raczkowski M., Hołodyńska A., Frąckowiak D., Ziółkowski A., Przewoźniak M., Rzeszutko U., Domańska I., Pszczolińska K., Łozowicka B., Kaczyński P., Rutkowska E., Jankowska M., Hrynko I., Szpyrka E., Rupar J., Matyaszek A., Kurdziel A., Podbielska M., Słowik-Borowiec M., Szponik M. 2015. Pozostałości środków ochrony roślin w płodach rolnych (rok 2013). [Pesticide residues in agricultural crops (2013)]. Progress in Plant Protection 55 (4): 423-439. DOI: 10.14199/ppp-2015-071

Pesticide Residue Monitoring Program. Fiscal Year 2014 Pesticide Report U.S. Food and Drug Administration. 2017a. https://www.fda. gov/media/103511/download [dostęp: 10.02.2020].

Pesticide Residue Monitoring Program. Fiscal Year 2015 Pesticide Report U.S. Food and Drug Administration. 2017b. https://www.fda. gov/media/108688/download [dostęp: 10.02.2020].

Report from the Commission to the European Parliament and the Council on the establishment of a European fund for minor uses in the field of plant protection products Brussels. 2014. Com (2014) 82 final, 18.02.2014.

Rozporządzenie(WE) nr 178/2002 Parlamentu Europejskiego i Rady z dnia 28 stycznia 2002 r. ustanawiające ogólne zasady i wymagania prawa żywnościowego, powołujące Europejski Urząd ds. Bezpieczeństwa Żywności oraz ustanawiające procedury w zakresie bezpieczeństwa żywności. 2002. Dz. Urz. L 31, s. 1 z dnia 01.02.2002 r. z późn. zm., polskie wydanie specjalne: rozdz. 15, t. 6, s. 463.

Rozporządzenie (WE) nr 396/2005 Parlamentu Europejskiego i Rady z dnia 23 lutego 2005 r. w sprawie najwyższych dopuszczalnych poziomów pozostałości pestycydów w żywności i paszy pochodzenia roślinnego i zwierzęcego oraz na ich powierzchni, zmieniające dyrektywę Rady 91/414/EWG. 2005. Dz. U. L 70 z 16.03.2005 r., s. 1.

Rozporządzenie Parlamentu Europejskiego i Rady (WE) NR 1107/2009 z dnia 21 października 2009 r. dotyczące wprowadzania do obrotu środków ochrony roślin i uchylające dyrektywy Rady 79/117/EWG i 91/414/EWG. 2009. Dz. U. L 309 z 24.11.2009 r., s. 1.

Rozporządzenie Komisji (UE) nr 16/2011 z dnia 10 stycznia 2011 r. ustanawiające środki wykonawcze dla systemu wczesnego ostrzegania o niebezpiecznych produktach żywnościowych i środkach żywienia zwierząt. 2011. Dz. Urz. L 6 z 10.01.2011 r., s. 7.

Rozporządzenie Ministra Rolnictwa i Rozwoju Wsi z dnia 27 listopada 2013 r. w sprawie pobierania próbek roślin, produktów roślinnych lub przedmiotów do badań na obecność pozostałości środków ochrony roślin. 2013. Dz. U. z 2013 r. poz. 1549.

Scientific Report of EFSA. 2016. The 2014 European Union report on pesticide residues in food. EFSA Journal 201614 (10): 4611,139 ss.

Scientific Report of EFSA. 2017. The 2015 European Union report on pesticide residues in food. EFSA Journal 2017 15 (4): 4791,134 ss.

Uchwała nr 161/2011 Rady Ministrów z dnia 16 sierpnia 2011 r. w sprawie ustanowienia programu wieloletniego pod nazwą „Ochrona roślin uprawnych z uwzględnieniem bezpieczeństwa żywności oraz ograniczenia strat w plonach i zagrożeń dla zdrowia ludzi, zwierząt domowych i środowiska". 2011.

Ustawa z dnia 18 grudnia 2003 r. o ochronie roślin. 2004. Dz. U. 2004 nr 11, poz. 95 z późn. zm., tekst jednolity z dnia 15.01 .2014 r.

Ustawa z dnia 25 sierpnia 2006 r. o bezpieczeństwie żywności i żywienia. 2010. Dz. U. 2010 nr 136, poz. 914, z późn. zm.

Ustawa z dnia z 8 marca 2013 r. o środkach ochrony roślin. 2013. Dz. U. z 2013 r. poz. 455.

Walorczyk S. 2008. Development of a multi-residue method for the determination of pesticides in cereals and dry animal feed using gas chromatography-tandem quadrupole mass spectrometry II. Improvement and extension to new analytes. Journal of Chromatography A 1208 (1-2): 202-214. DOI: 10.1016/j.chroma.2008.08.068

Walorczyk S., Drożdżyński D. 2011. Development and validation of a routine multiresidue method for determining 140 pesticides in fruits and vegetables by gas chromatography/tandem quadrupole mass spectrometry. Journal of AOAC International 94 (5): $1625-1642$. DOI: 10.5740/jaoacint.10-329 